Article

\title{
Study of Mixed-Mode Cracking of Dovetail Root of an Aero-Engine Blade Like Structure
}

\author{
Giacomo Canale ${ }^{1}$, Moustafa Kinawy ${ }^{1, *}$, Angelo Maligno ${ }^{1}$, Prabhakar Sathujoda ${ }^{2}$ and \\ Roberto Citarella ${ }^{3}$ iD \\ 1 Institute of Innovative Sustainable Energy, University of Derby, Kedleston Road, Derby DE1 3HD, UK \\ 2 Department of Mechanical and Aerospace Engineering, Bennett University, \\ Greater Noida 201310, Uttar Pradesh, India \\ 3 Department of Industrial Engineering, University of Salerno, 84084 Salerno, Italy \\ * Correspondence: M.Kinawy@derby.ac.uk
}

Received: 19 July 2019; Accepted: 30 August 2019; Published: 12 September 2019

check for updates

\begin{abstract}
Aerospace structures must be designed in such a way so as to be able to withstand even more flight cycles and/or increased loads. Damage tolerance analysis could be exploited more and more to study, understand, and calculate the residual life of a component when a crack occurs in service. In this paper, the authors are presenting the results of a systematic crack propagation analysis campaign performed on a compressor-blade-like structure. The point of novelty is that different blade design parameters are varied and explored in order to investigate how the crack propagation rate in low cycle fatigue $(\mathrm{LCF}$, at $\mathrm{R}$ ratio $\mathrm{R}=0)$ could be reduced. The design parameters/variables studied in this work are: (1) The length of the contact surfaces between the dovetail root and the disc and (2) their inclination angle (denoted as "flank angle" in the aero-engine industry). Effects of the friction coefficient between the disc and the blade root have also been investigated. The LCF crack propagation analyses have been performed by recalculating the stress field as a function of the crack propagation by using the FRacture ANalysis Code (Franc3 $\left.\mathrm{D}^{\circledR}\right)$.
\end{abstract}

Keywords: LCF; crack propagation; blade-disc-Franc3D; mixed-mode cracking

\section{Introduction}

Fans, compressors, and turbine blades of aero-engines are highly stressed components, especially in the contact area between the blade root and the disc slot [1]. This is due both to the high rotational speed of the shaft and to the aerodynamic load. Consequently, cracks may appear both in low cycle fatigue (LCF, defined in the aero-engine industry as the fatigue caused by the application and release of the main centrifugal and aerodynamic load, with stress ratio $\mathrm{R}=0$ ) and high cycle fatigue (HCF, defined in the aero-engine industry as the fatigue induced by the vibration loads). Crack propagation has already been studied in fan, compressor, or turbine blades [1-7]. In recent times, a powerful and simple tool for crack propagation analyses has been released and used in several academic and industrial works: Franc3D [8,9]. It is a state-of-the-art 3D crack propagation tool developed by Cornell University. Franc3D has proven effective in a variety of engineering problems of crack propagation [10-13].

\section{Problem Description}

The aim of this work is to study the effect on crack propagation of two important design variables of the geometry of the dovetail root in a compressor blade-like structure like the one shown in Figure 1. 


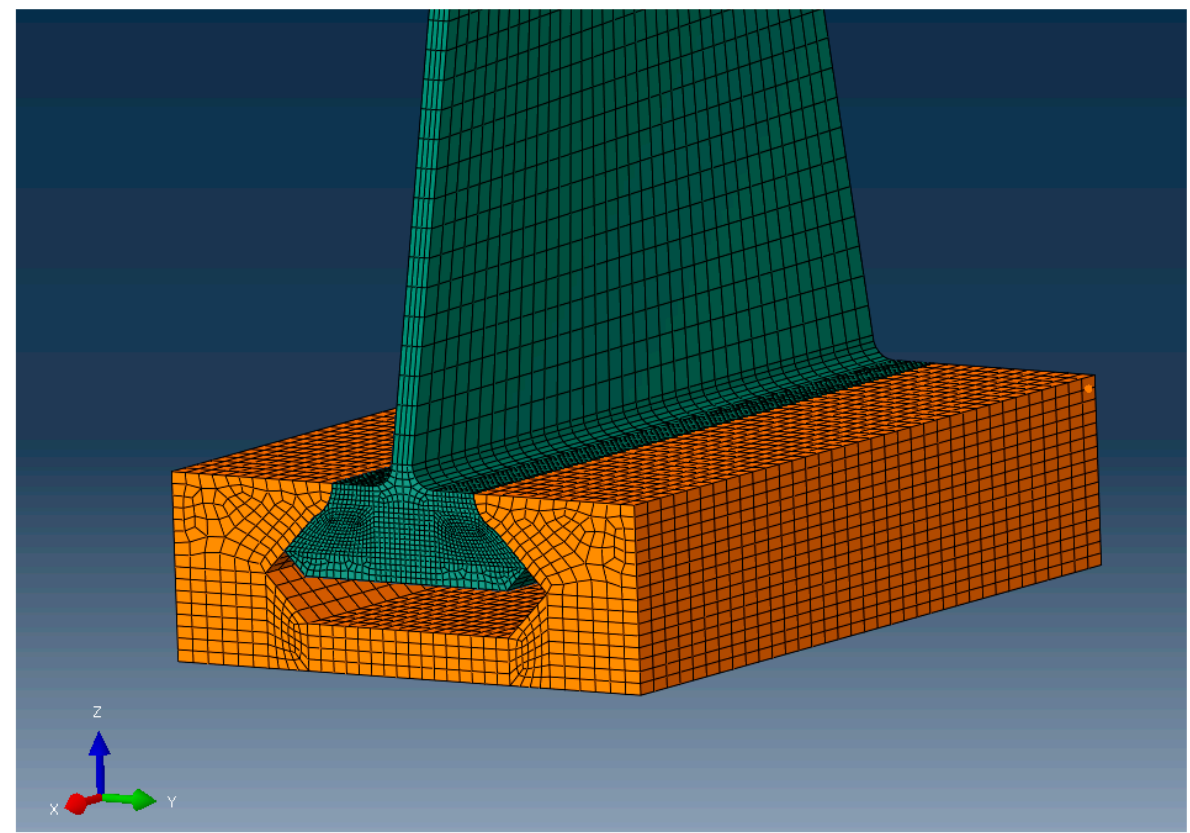

Figure 1. A dovetail joint between the compressor-blade-like structure and the disc representative geometry.

The design variables are shown in Figure 2, on a cross section sketch of the 3D root. They are:

- The length of the contact flank (Figure 2).

- $\quad$ The flank angle $\vartheta$ (Figure 2).

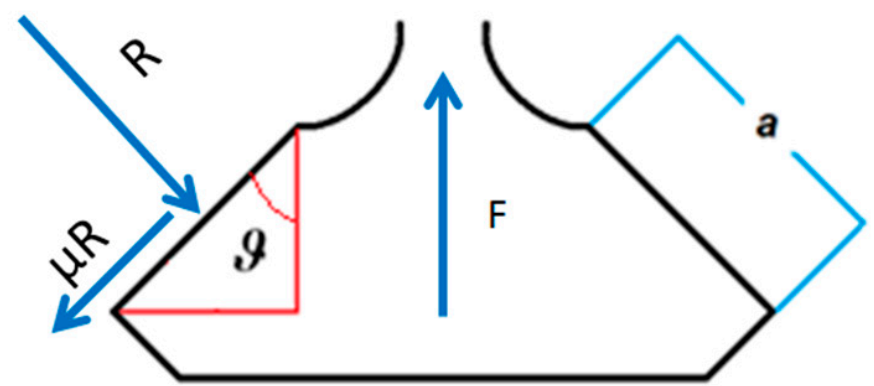

\section{a : Flank length \\ F: centrifugal force $\boldsymbol{\vartheta}$ :Flank angle $R$ : Reaction force}

Figure 2. The flank length and flank angle, the design variables in this study.

Three flank design angles were investigated: $30^{\circ}, 45^{\circ}$, and $60^{\circ}$. For each of these flank angles, two flank lengths were investigated. The short flank was $6.5 \mathrm{~mm}$ whilst the long flank was $13 \mathrm{~mm}$. For only one specific case (each analysis takes around 1 week to run on a 12 processors PC), the $45^{\circ}$ model with a short flank, the effect of two different friction coefficients ( 0.1 and 0.7$)$ was studied in order to understand the difference between a perfect frictionless contact and the contact between two worn surfaces.

For the same geometry, two different crack propagation criteria were investigated: A crack driven by an opening mode $\mathrm{K}_{\mathrm{I}}$ and a crack driven by mixed-mode represented by $\mathrm{K}_{\mathrm{eq}}$ [14]. All the crack propagation analyses were performed under $L C F$, with a ratio of $\mathrm{R}=0$. It is important to remark that in the aero-engine industry, LCF is intended as the cyclic application of the major load (centrifugal force and aerodynamic pressure in the case of a blade) and its release. The R-ratio is 0 . In other words, in LCF, no vibration is taken into account. Linear elastic fracture mechanics can still be applied as the 
material is far from yielding, with the only exception of a small region close to the crack tip. Given that $R=0$, the notation " $K$ " or " $\Delta K$ " is therefore used equivalently in this paper.

The initial flaw was assumed as a corner crack. This option was given by Barlow and Chandra in Barlow et al. [1]. The other option to be used, as discussed in [1], would be a semi-elliptic side crack. In reference [1], experimental evidence of these options was also provided.

In this paper, the authors chose the corner crack as the stress field calculated with a finite element model which gave its peak towards the edge of the contact. A crack is more likely to start there.

\section{Finite Element (FE) Model of the Blade and Disc Slot}

An overview of the blade-like structure used in this assessment is given in Figure 1. In reality, for the purpose of this study, six different AbaqusßFE models were prepared and they are listed in Table 1. All the models have most dimensions in common. Only the angle of the root and the flank length vary from one model to the other. The airfoil thickness $(t=2 \mathrm{~mm})$, root slot width $(\mathrm{s}=14 \mathrm{~mm})$, blade axial length $(1=70 \mathrm{~mm})$, and airfoil height $(\mathrm{h}=150 \mathrm{~mm})$ are kept constant (Figures 3 and 4$)$. The original angle of twist (undeformed shape) is $30^{\circ}$.

Table 1. Models prepared for the study presented in this paper.

\begin{tabular}{|c|c|c|}
\hline Model Name & 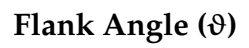 & Flank Length (a) $\mathrm{mm}$ \\
\hline 45_short & $45^{\circ}$ & 6 \\
\hline 45_long & $45^{\circ}$ & 11 \\
\hline 30_short & $30^{\circ}$ & 6 \\
\hline 30_long & $30^{\circ}$ & 11 \\
\hline 60_short & $60^{\circ}$ & 6 \\
\hline 60_long & $60^{\circ}$ & 11 \\
\hline
\end{tabular}

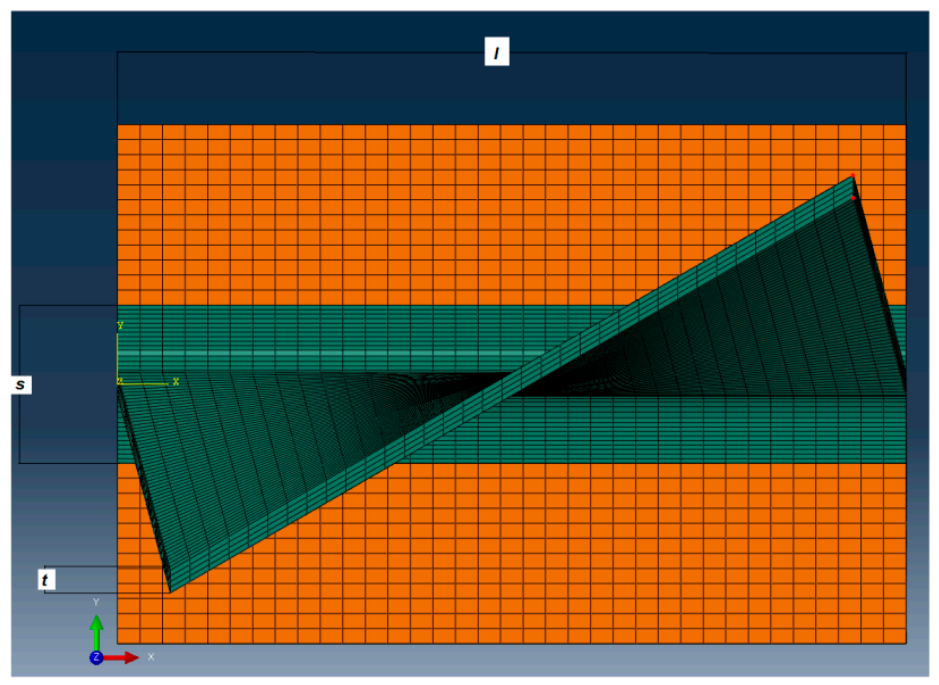

Figure 3. Non-variable dimensions in each of the six FE models. 


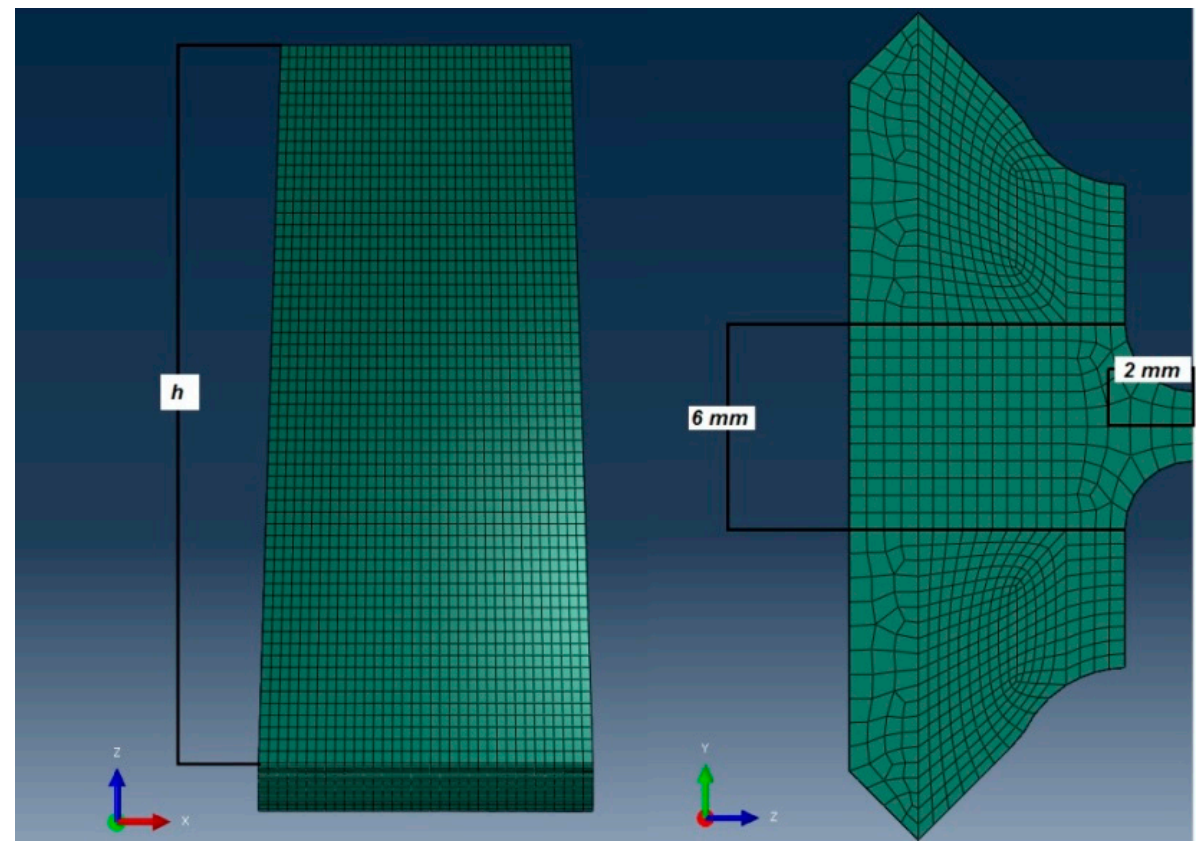

Figure 4. Airfoil length and transition area details.

The blade and disc-like FE models were originally meshed with HEX20 (20 nodes bricks, quadratic elements). Each model was meshed with c.a. 80,000 elements. Static analyses were run before starting the crack propagation study to check the model convergence. It is important to remark that a sub-model of the root was re-meshed by Franc3D itself when the crack was propagating. Franc3D uses TET10 elements (10 nodes tetrahedral elements). An image of the re-meshing is shown in Figure 5.

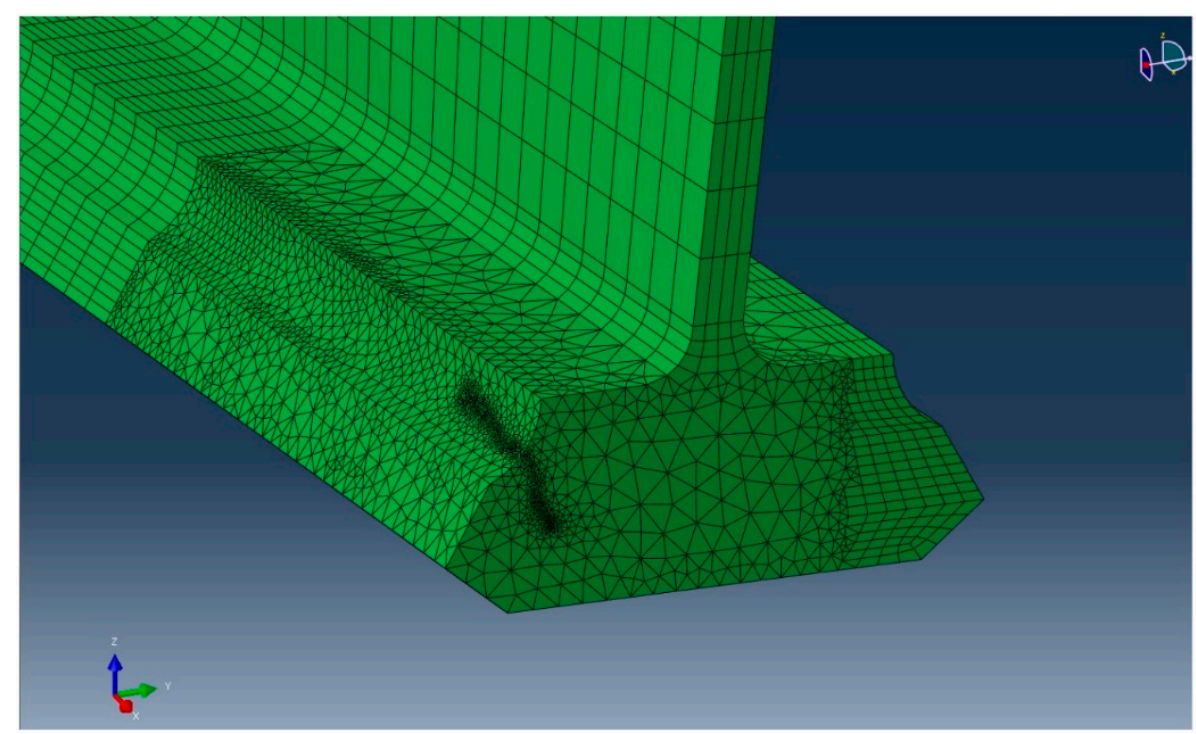

Figure 5. Sub-model containing the crack. The mesh is automatically generated within Franc3D at each iteration.

The blade was made from Ti-6Al-4V. Forging is the manufacturing process used for a small blade like the one studied in reference [15]. For bigger size blades, like compressor rotors of a big turbofan aero-engine, forging can be preceded by a machining operation [16]. Even if the structure is forged, isotropic material properties were assumed for the work proposed in this paper. 


\subsection{Loads and Boundary Conditions}

The base of the block representing the disc is fixed in all the directions as shown in Figure 6. The blade was not restrained in any way and was free to move. Only a surface-to-surface contact was defined along the flanks at the interface of the disc/blade (Figure 7). A "hard" contact between the blade and the block was used with a friction coefficient of 0.7. A similar approach has already been used by Ma et al. [17]. Three different loads are applied to the structure. They are given in Table 2.

Table 2. Loads applied to all the models.

\begin{tabular}{ccc}
\hline $\begin{array}{c}\text { Shaft Rotation Speed } \\
\text { (RPM) }\end{array}$ & $\begin{array}{c}\text { Pressure Side } \\
\text { (Pressure Value, MPa) }\end{array}$ & $\begin{array}{c}\text { Suction Side } \\
\text { (Pressure Value, MPa) }\end{array}$ \\
\hline 9550 & 0.18 & 0.16 \\
\hline
\end{tabular}

The authors are fully aware that real loads may be slightly higher than those really measured in a real blade of a large turbofan. However, this does not affect the generality of the procedure and the results of the design.

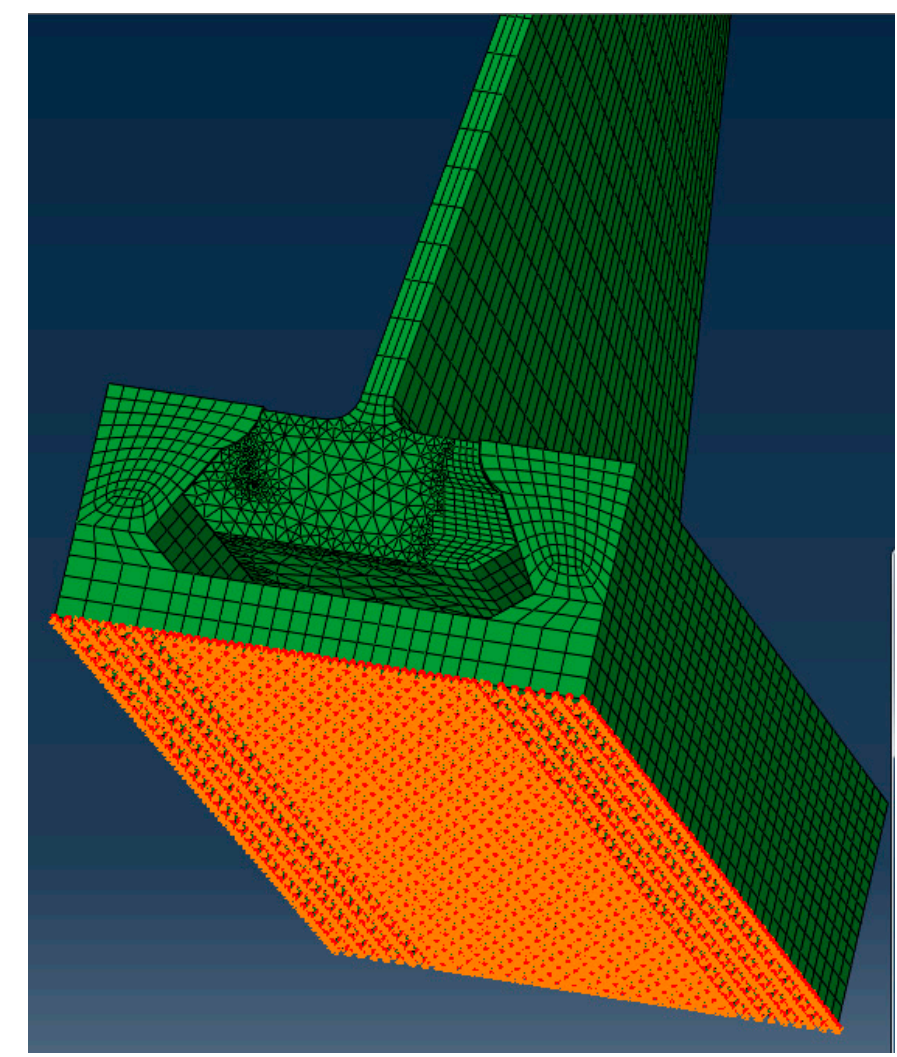

Figure 6. Boundary conditions at the bottom surface of the disc block. 


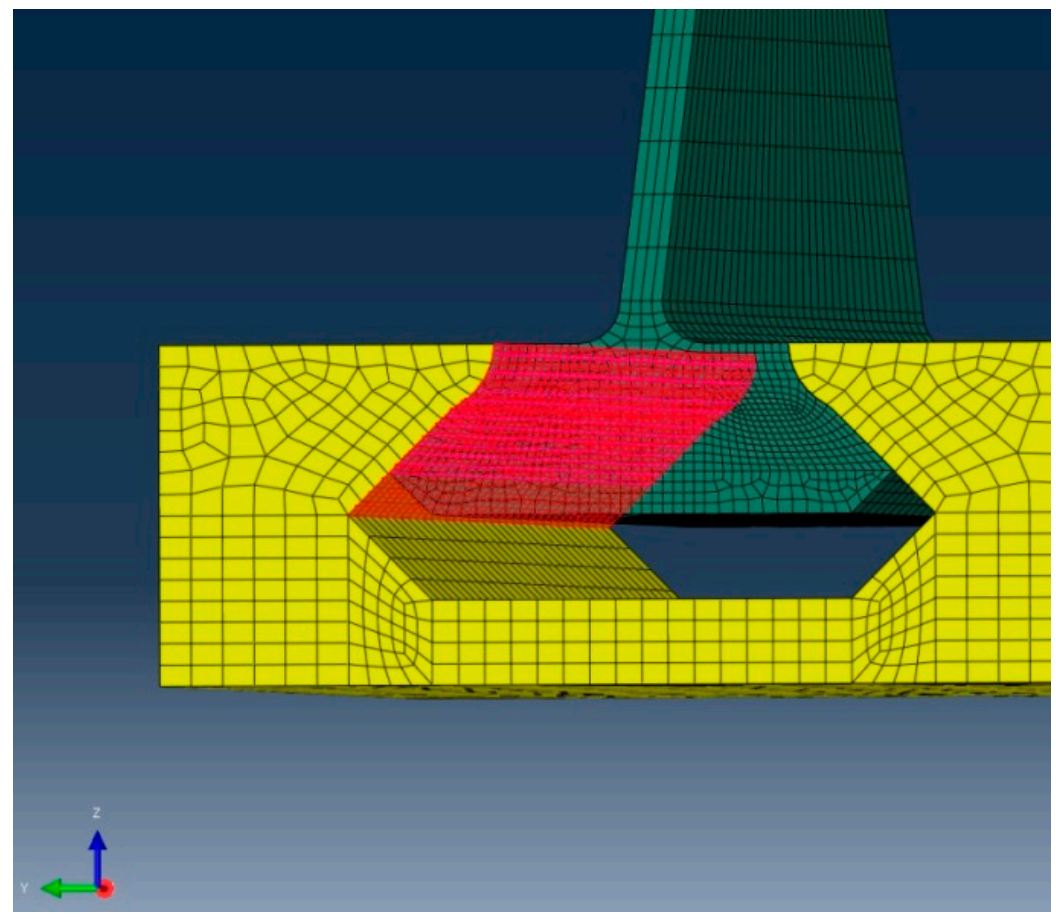

Figure 7. Surface to surface contact definition at the root flanks.

\subsection{Material Properties and Crack Propagation Law}

The material properties were taken from the work of Al-Emrani et al. [11]. The elastic material properties are given in Table 3. All the analyses were performed assuming a metal temperature $=$ $20^{\circ} \mathrm{C}$. This is quite far from reality, as a gas turbine blade generally works at much hotter conditions. The high temperature will influence material parameters such as Young's modulus and toughness and will also change the friction coefficient at the blade-disc interface. However, for the sake of simplicity, the ambient temperature was assumed as this assumption does not affect the generality of the design procedure.

Table 3. Elastic properties of Ti-6Al-4V used in this paper.

\begin{tabular}{|c|c|c|}
\hline E (MPa) & $\mathbf{v}$ & $\rho\left(\mathrm{Mg} / \mathrm{mm}^{3}\right)$ \\
\hline 115,000 & 0.33 & $4.43 \times 10^{-9}$ \\
\hline
\end{tabular}

A Paris law was used to calculate the number of LCF cycles. The Paris law reported by Richard and Sander [13] in his book is written in the form:

$$
\frac{d a}{d N}=C \Delta K^{n}
$$

where:

- $\quad a$ is the crack length

- $\quad N$ is the number of LCF cycles

- $\quad$, $n$ are constants

- $\Delta K$ is the stress intensity factor range between the maximum and minimum stress field (equals to zero in case of LCF). 
The crack propagation data used in the analysis are given in Table 4, and they are all taken from Reference [1], in which $\mathrm{K}_{\mathrm{IC}}$, the reported value of fracture toughness, is $1739 \mathrm{MPa} \cdot \mathrm{mm}^{0.5}$. For this paper, however, a design value of $869.5 \mathrm{MPa} \mathrm{mm}{ }^{0.5}$ was conservatively assumed. In other words, a safety factor of 2 was used for design purposes.

Table 4. Crack propagation (Paris law) for the Ti-6Al-4Va used in this paper (data adapted from [1]).

\begin{tabular}{cccc}
\hline $\mathbf{K}_{\mathrm{IC}}\left[\mathrm{MPa} \mathrm{\mathbf { } \mathrm { mm } ^ { 0 . 5 } ]}\right.$ & $\mathbf{d a} / \mathbf{d N}$ Parameter C & $\mathbf{d a} / \mathbf{d N}$ Parameter $\mathbf{n}$ & $\Delta \mathbf{K}_{\text {th }}\left[\mathbf{M P a} \mathbf{~ m m}^{\mathbf{0 . 5}}\right]$ \\
\hline 869.5 & $1.77 \times 10^{-14}$ & 3.667 & 121.6 \\
\hline
\end{tabular}

It is quite interesting to compare the relevant crack propagation data from different sources of the open literature. Three examples, for values of $\mathrm{R}$ not greater than 0.1 , are given in Table 5 . In these three examples, the Paris law coefficients have been calculated for a law of the mathematical form as per Equation (1).

Table 5. Crack propagation parameters data for Ti-6Al-4V reported in different literature. Paris Coefficient (C) units *are compatible with (da/dN) in mm/cycle.

\begin{tabular}{|c|c|c|c|c|}
\hline Study & $\mathrm{K}_{\mathrm{IC}}\left[\mathrm{MPa} \mathrm{mm}^{0.5}\right]$ & $\mathrm{da} / \mathrm{dN}$ Parameter C & $\mathrm{da} / \mathrm{dN}$ Parameter $\mathbf{n}$ & $\Delta \mathrm{K}_{\mathrm{th}}\left[\mathrm{MPa} \mathrm{mm} \mathrm{m}^{0.5}\right]$ \\
\hline Barlow [1] & 1739 & $1.7700 \times 10^{-14}$ & 3.667 & 121.6 \\
\hline Zhu [18] & 1900 & $0.5085 \times 10^{-14}$ & 3.14 & 163.8 \\
\hline Ritchie [19] & 800 & $4.8340 \times 10^{-14}$ & 2.5 & 145.46 \\
\hline
\end{tabular}

The reader can appreciate how different the parameters can be. A set of ad-hoc experiments are therefore needed for the specific engineering application.

In order to predict the number of cycles from the $\mathrm{K}_{\mathrm{th}}$ to the unstable propagation of the crack $\left(\mathrm{K}_{\mathrm{IC}}\right)$, the Paris law (Equation (1)) has been integrated (clearly, the Paris law is not applicable to the whole range from $K_{\text {th }}$ to $K_{c}$ so the crack length range was such that the near threshold and the near fracture parts of the da/dN- $\Delta \mathrm{K}$ curve was not involved).

\section{Franc3D Simulations Set-Up}

Adequate sub-models have been produced from the original Abaqus model. An initial crack, semi-circular, with a radius $=0.5 \mathrm{~mm}$, was inserted c.a. $1.4 \mathrm{~mm}$ above the edge of bedding. The initial crack position and orientation (perpendicular to the surface), shown in Figure 8, were kept consistent in all the analysis performed.

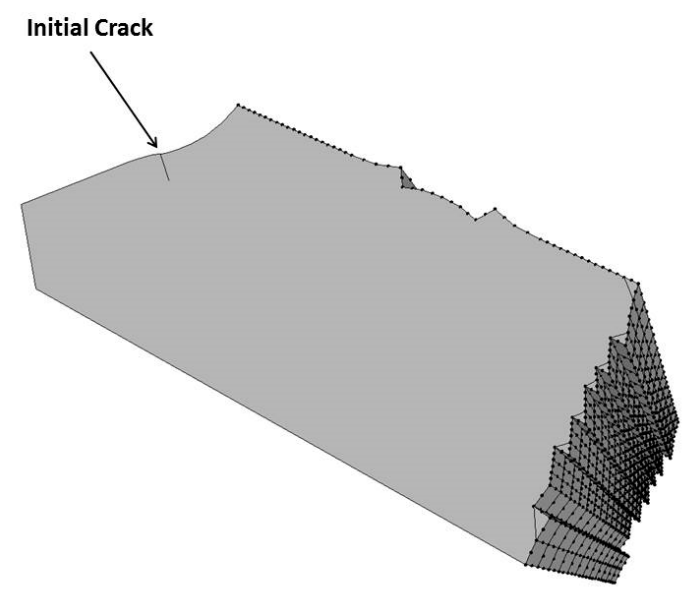

Figure 8. Initial flaw position. 
A quasi-static crack propagation analysis was performed. Dynamic effects such as the wave propagation were not taken into account. The "maximum fracture energy" was chosen as an extension criterion [20]. A kink angle perpendicular to the maximum principal stress was chosen. $K_{\text {eq }}$ from [14] has been considered equal to $\mathrm{K}_{\mathrm{I}}$. This assumption is valid as long as the values of $\mathrm{K}_{\mathrm{II}}$ and $\mathrm{K}_{\mathrm{III}}$ are small compared to the stress intensity in mode I. The validity of this assumption will be discussed in Section 5 when discussing the results. A comparison between $\mathrm{K}_{\mathrm{I}}$ and $\mathrm{K}_{\mathrm{eq}}$ was also performed for the $45^{\circ}$ flank angle with short flank length geometry.

Franc3D uses a displacement correlation technique [21] to calculate the stress intensity factors. The displacements on the crack surface (opening, sliding, and tearing) are directly related to the three different stress intensity factors. Stress intensity factors calculated with Franc3D have been extensively validated with analytical solutions in some works available in the open literature [22].

\section{Results and Discussion}

For each of the analysis performed, the crack evolution was studied. The stress intensity factors $\mathrm{K}_{\mathrm{I}}$, $\mathrm{K}_{\mathrm{II}}$, and $\mathrm{K}_{\mathrm{III}}$, were plotted as a function of the crack length. These values of the stress intensity factors were plotted along different crack paths. In all the performed analyses, the crack has two directions of propagation, the main leg, along the axial direction of the blade (and of the engine) and the secondary leg, towards the base of the root. An image of general crack propagation is given in Figure 9.

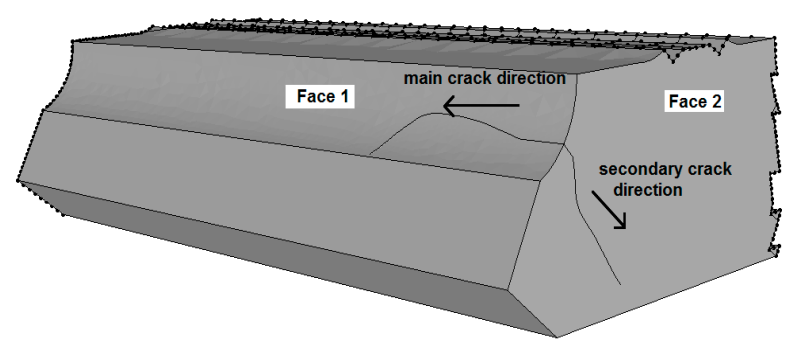

Figure 9. Two leading crack front directions.

All the results presented are given along three specific crack paths named:

- $5 \%$ of the crack front (in other words, very close to Face 2 shown in Figure 7).

- $50 \%$ of the crack front.

- $\quad 95 \%$ of the crack front (in other words, the stress intensity is calculated along a crack line very close to Face 1 of Figure 7, along the main crack direction).

A graphic illustration of this crack front is given in Figure 10.

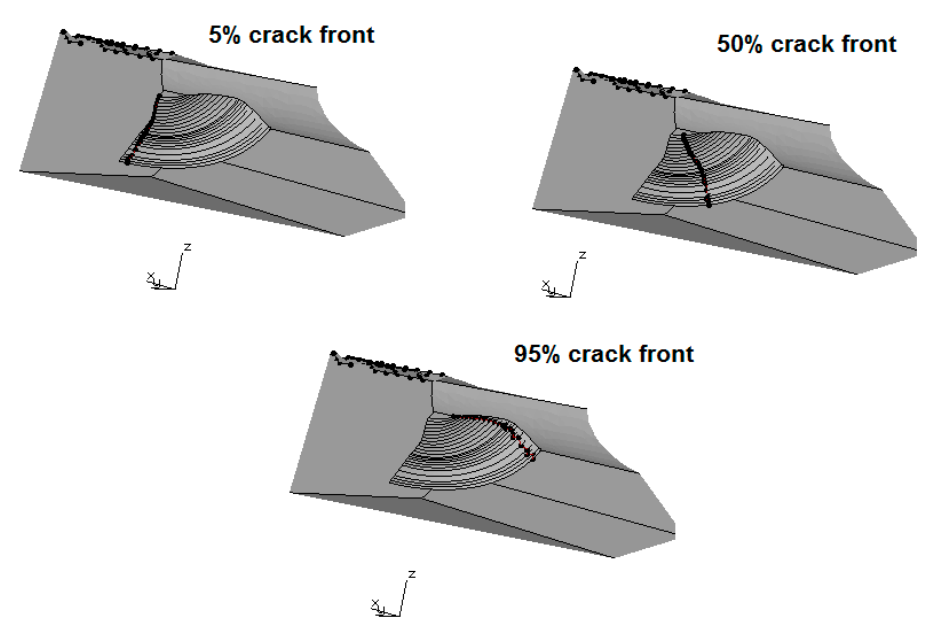

Figure 10. Three crack paths where the stress intensity was computed. 
The stress intensity is given in MPa $\mathrm{mm}^{0.5}$ whilst the crack length is given in $\mathrm{mm}$.

\subsection{The $30^{\circ}$ Flank Angle}

Two different flank lengths were investigated as design variables when studying the $30^{\circ}$ flank angle, a short flank and a long flank, as per the values given in Table 1. The results of $\mathrm{K}_{\mathrm{I}}, \mathrm{K}_{\mathrm{II}}$, and $\mathrm{K}_{\mathrm{III}}$ as a function of the crack length are presented for the three different crack fronts. The crack shape of the short flank angle is shown in Figure 11.

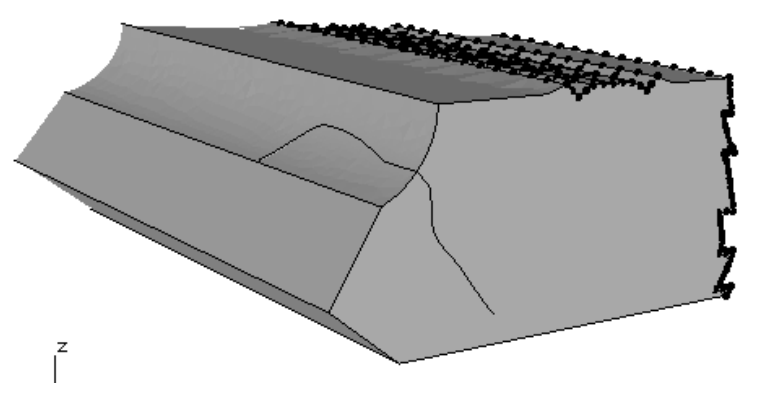

Figure 11. The $30^{\circ}$ angle, short flank crack shape.

The stress intensity values along the crack fronts are shown in Figure 12.
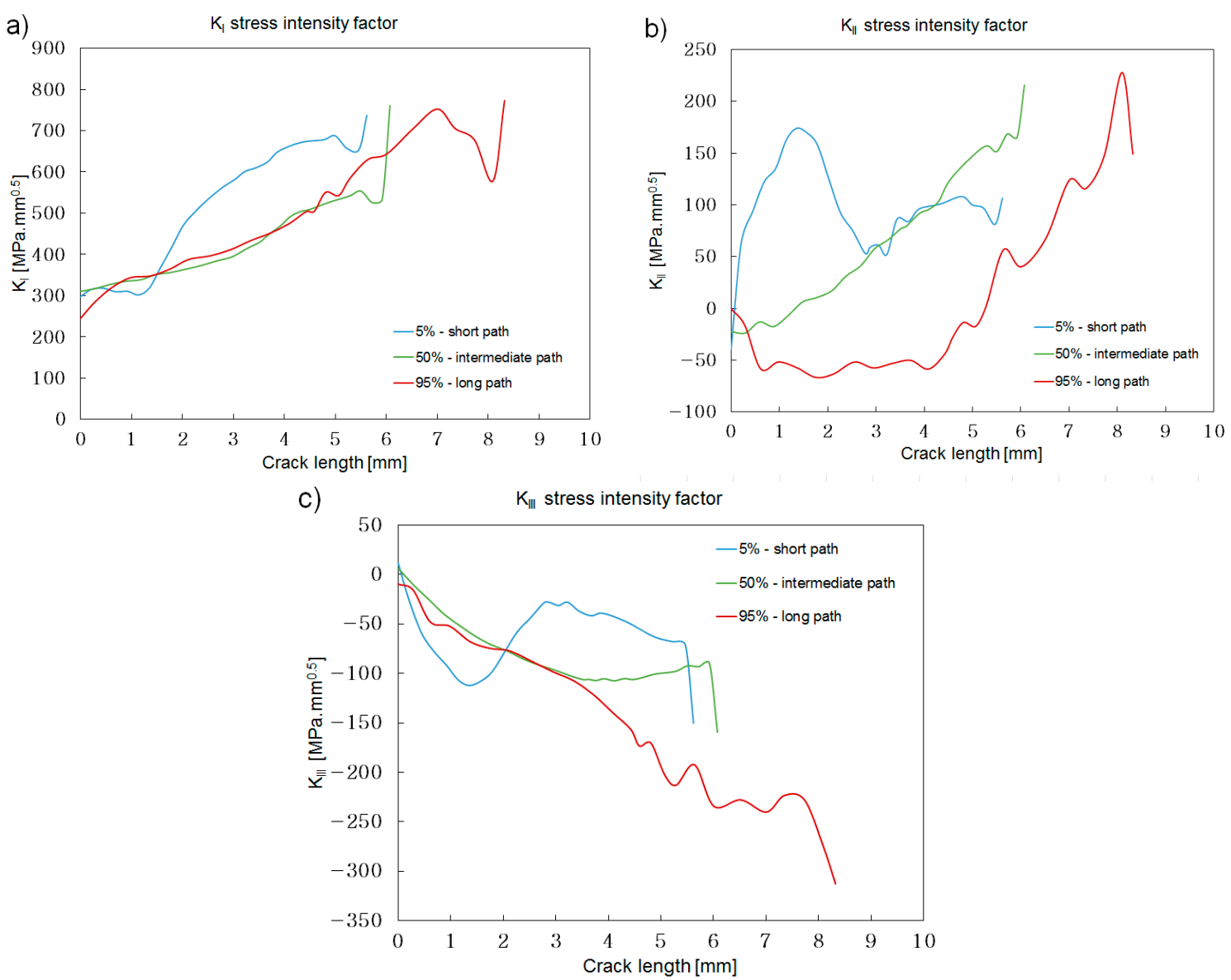

Figure 12. The $30^{\circ}$ angle, short flank stress intensity along the three crack paths selected: (a) $\mathrm{K}_{\mathrm{I}} ;$ (b) $\mathrm{K}_{\mathrm{II}}$; (c) $\mathrm{K}_{\mathrm{III}}$. 
$\mathrm{K}_{\mathrm{I}}$ is the biggest contributor to the crack propagation. $\mathrm{K}_{\mathrm{II}}$, however, has no negligible values, especially at large crack lengths (c.a. $8 \mathrm{~mm}$ crack length). This suggests that the analysed geometry may not be strictly dominated by mode I opening. An analogous consideration can be made for $\mathrm{K}_{\mathrm{III}}$, whose value is not negligible compared to $\mathrm{K}_{\mathrm{I}}$, especially when the crack becomes relatively large. This trend is more accentuated when the $95 \%$ crack front is considered. The kinks in the plots (Figure 12) towards the end of the simulation (when the crack is large) indicate the crack has reached the edge of bedding, and therefore hitting a numeric singularity. The simulation was therefore stopped. Similar results were obtained when the long flank geometry was analysed. The crack shape obtained with the simulation of the long flank is shown in Figure 13. The stress intensity factors are shown in Figure 14.

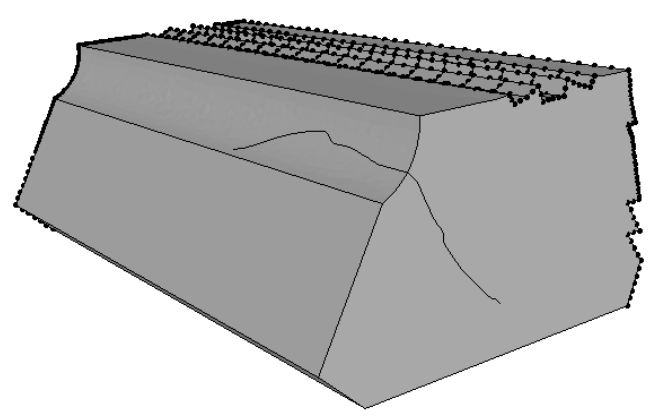

Figure 13. The $30^{\circ}$ angle, long flank crack shape.
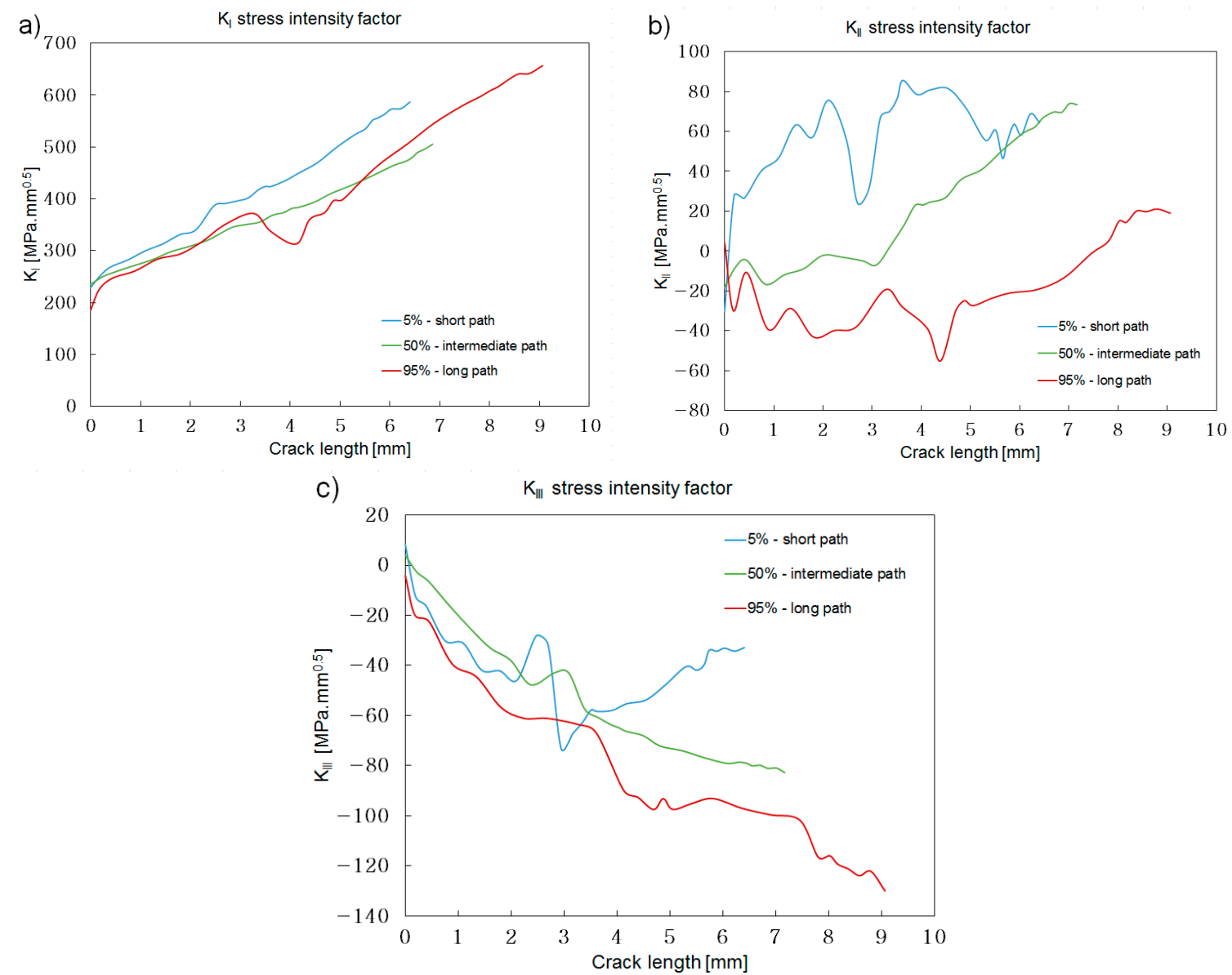

Figure 14. The $30^{\circ}$ angle, long flank. Stress intensity along the three crack paths selected: (a) $\mathrm{K}_{\mathrm{I}}$; (b) $\mathrm{K}_{\mathrm{II}}$; (c) $\mathrm{K}_{\mathrm{III}}$. 
In this case, on the other hand, the contribution of $\mathrm{K}_{\mathrm{II}}$ to the crack propagation is negligible. The contribution of $\mathrm{K}_{\mathrm{III}}$, as per the $30^{\circ}$ short flange geometry, starts to be significantly important when the crack becomes longer. The crack is therefore not only dominated by opening mode I, but also by a strong shear component, as was suggested by the authors of [11].

\subsection{The $60^{\circ}$ Flank Angle}

Short and long flank lengths have been studied also for the $60^{\circ}$ flank angle variant. The final crack shape of the $60^{\circ}$ short flank angle is shown in Figure 15.

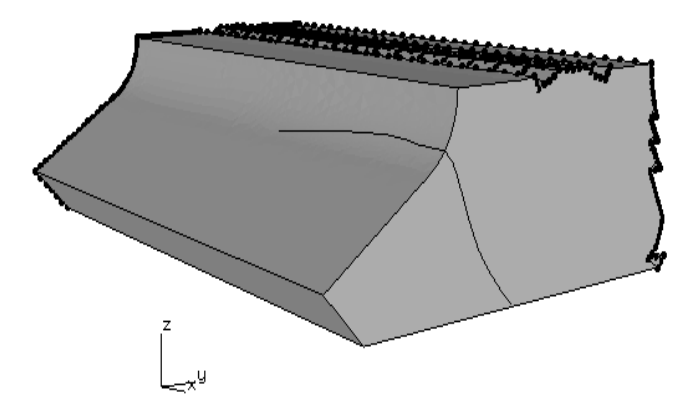

Figure 15. The $60^{\circ}$ angle, short flank crack shape.

The stress intensities are given in Figure 16.
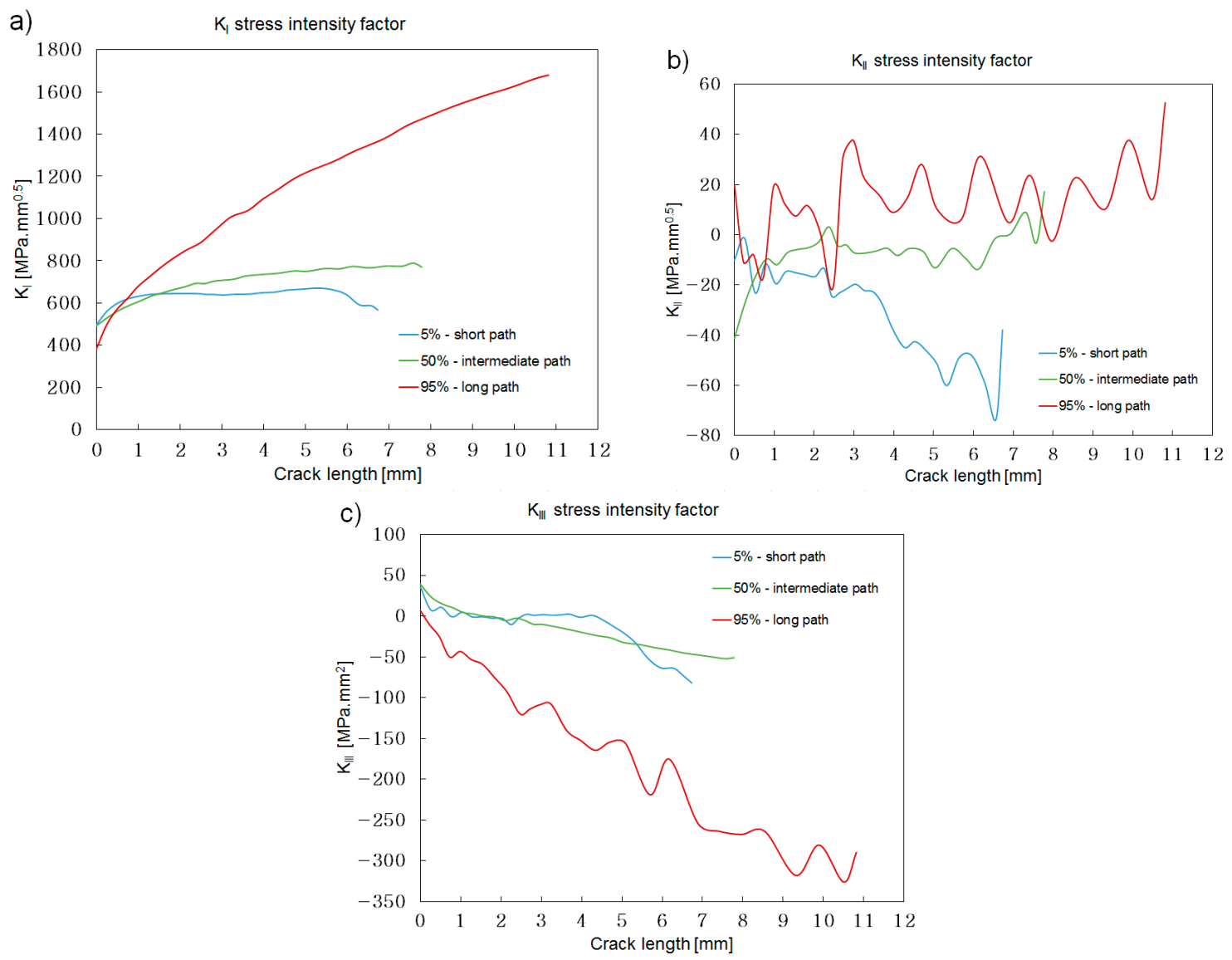

Figure 16. The $60^{\circ}$ angle short flank. Stress intensity along the three crack paths selected: (a) $\mathrm{K}_{\mathrm{I}}$; (b) $\mathrm{K}_{\mathrm{II}}$; (c) $\mathrm{K}_{\mathrm{III}}$. 
It can be easily noted that also in this case, the stress intensity drove the crack more rapidly towards an unstable growth located at $95 \%$ of the crack front (the portion of the crack closer to the edge of the dovetail contact). The contribution of $\mathrm{K}_{\mathrm{II}}$ is negligible, whilst for the "long" crack, i.e., when the crack becomes longer, the contribution of $\mathrm{K}_{\mathrm{III}}$ is quite important.

The crack shape of the long flank geometry option is shown in Figure 17. The stress intensities for the same geometry are given in Figure 18.

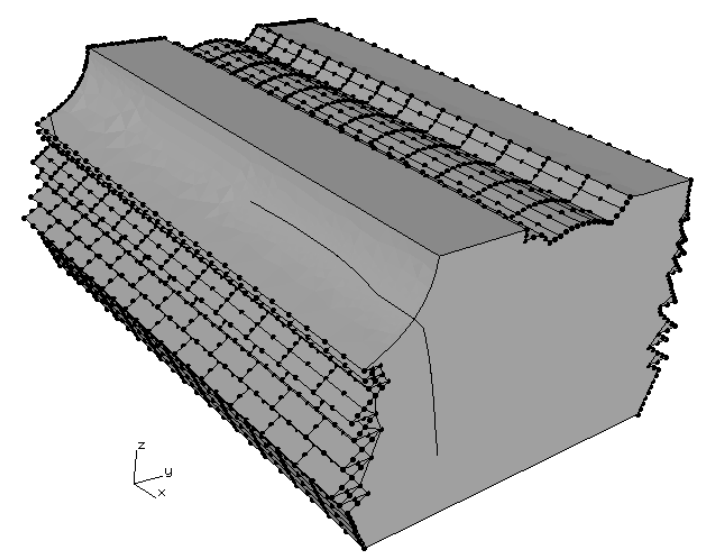

Figure 17. The $60^{\circ}$, long flank crack shape.
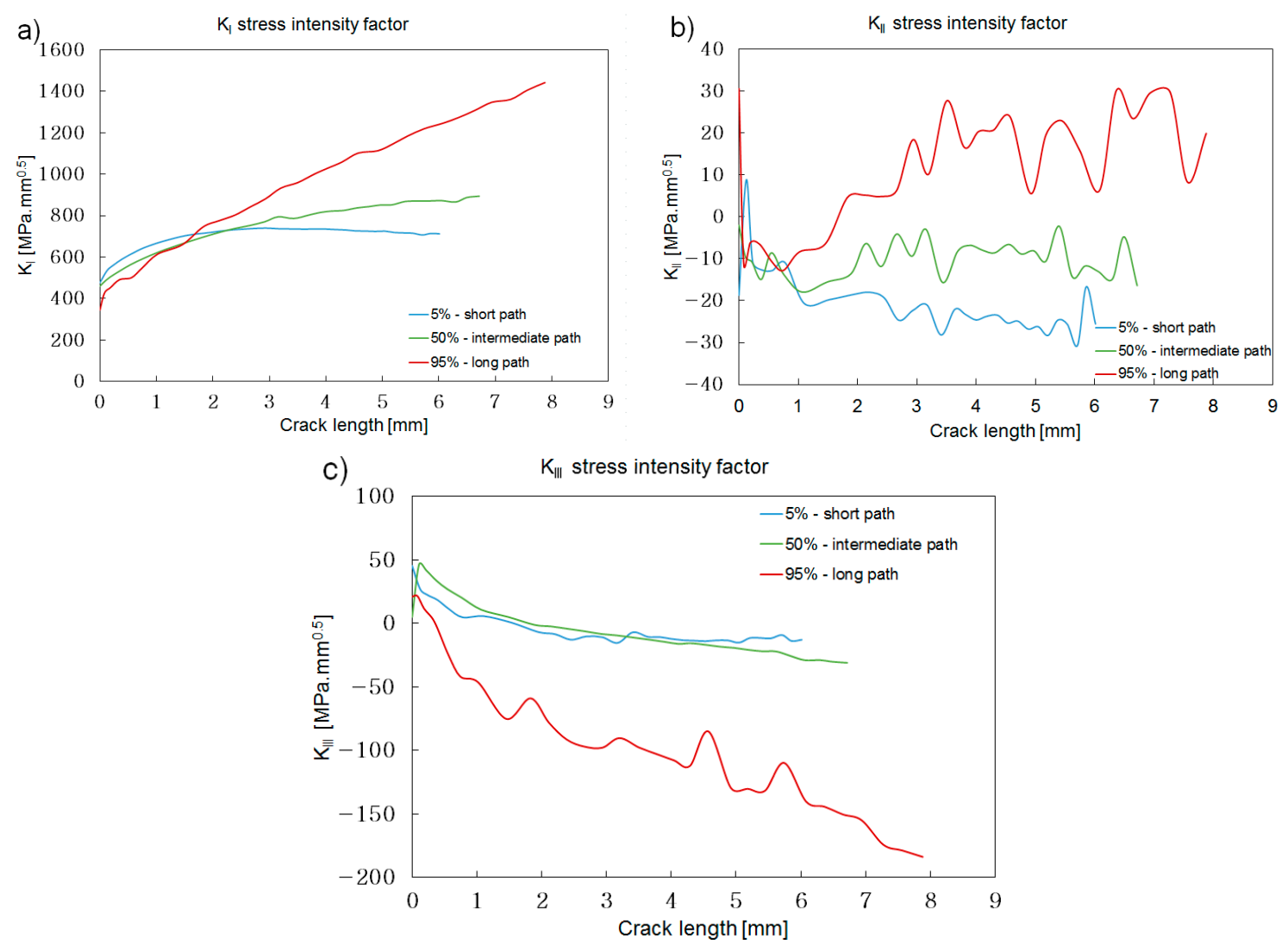

Figure 18. The $60^{\circ}$ long flank. Stress intensity along the three crack paths selected: (a) $\mathrm{K}_{\mathrm{I}}$; (b) $\mathrm{K}_{\mathrm{II}}$; (c) $\mathrm{K}_{\mathrm{III}}$.

\subsection{The $45^{\circ}$ Flank Angle}

The crack shape of the $45^{\circ}$ short flank angle is shown in Figure 19. 


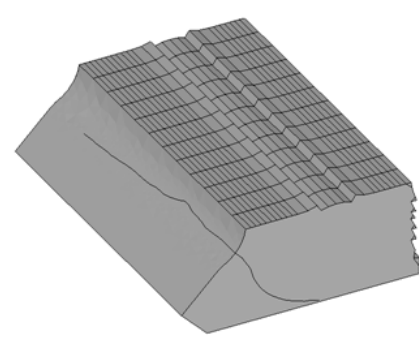

(a)

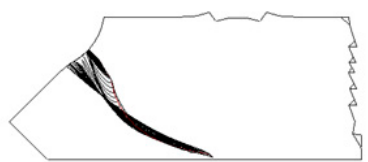

(b)

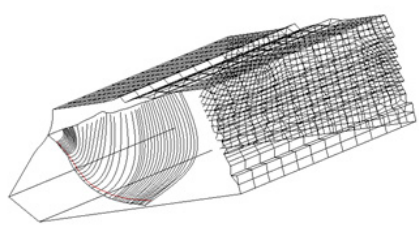

(c)

Figure 19. The $45^{\circ}$ angle, short flank crack shape. (a) External top view of the crack extension; (b) Front view of the crack extension; (c) isometric view.

The stress intensities are shown in Figure 20. Also, for this geometry, the critical crack path is along the direction of the engine axis (95\% of the crack front). There is a pronounced $\mathrm{K}_{\mathrm{II}}$ contribution at $5 \%$ and $50 \%$ of the crack front. Whereas $\mathrm{K}_{\mathrm{III}}$ has a big influence at the $95 \%$ crack front growth.
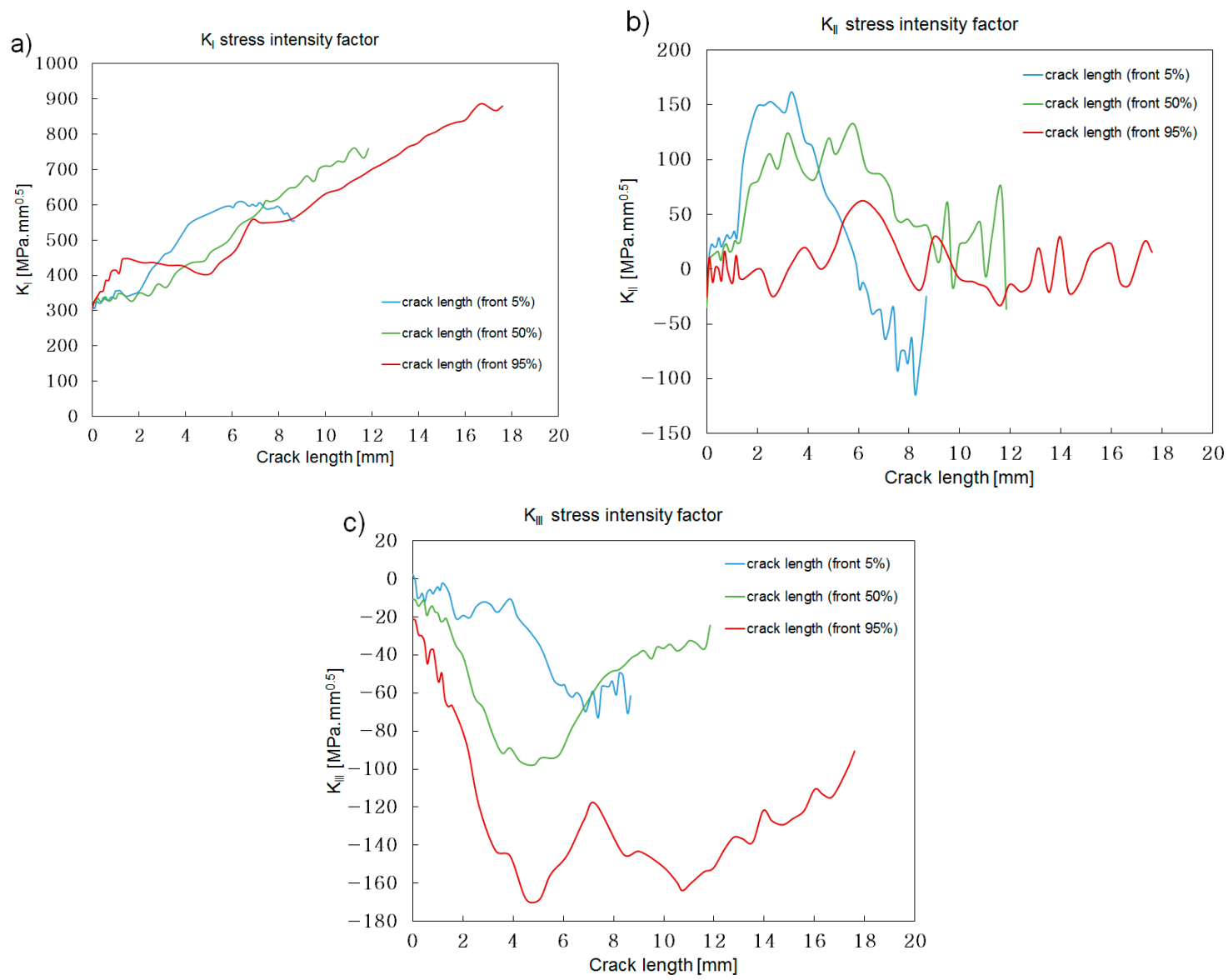

Figure 20. The $45^{\circ}$ angle, short flank. Stress intensity along the three crack paths selected: (a) $\mathrm{K}_{\mathrm{I}}$; (b) $\mathrm{K}_{\mathrm{II}}$; (c) $\mathrm{K}_{\mathrm{III}}$.

Analogously to the other geometries, the long flank of the $45^{\circ}$ option was also analysed. The stress intensities are given in Figure 21. 

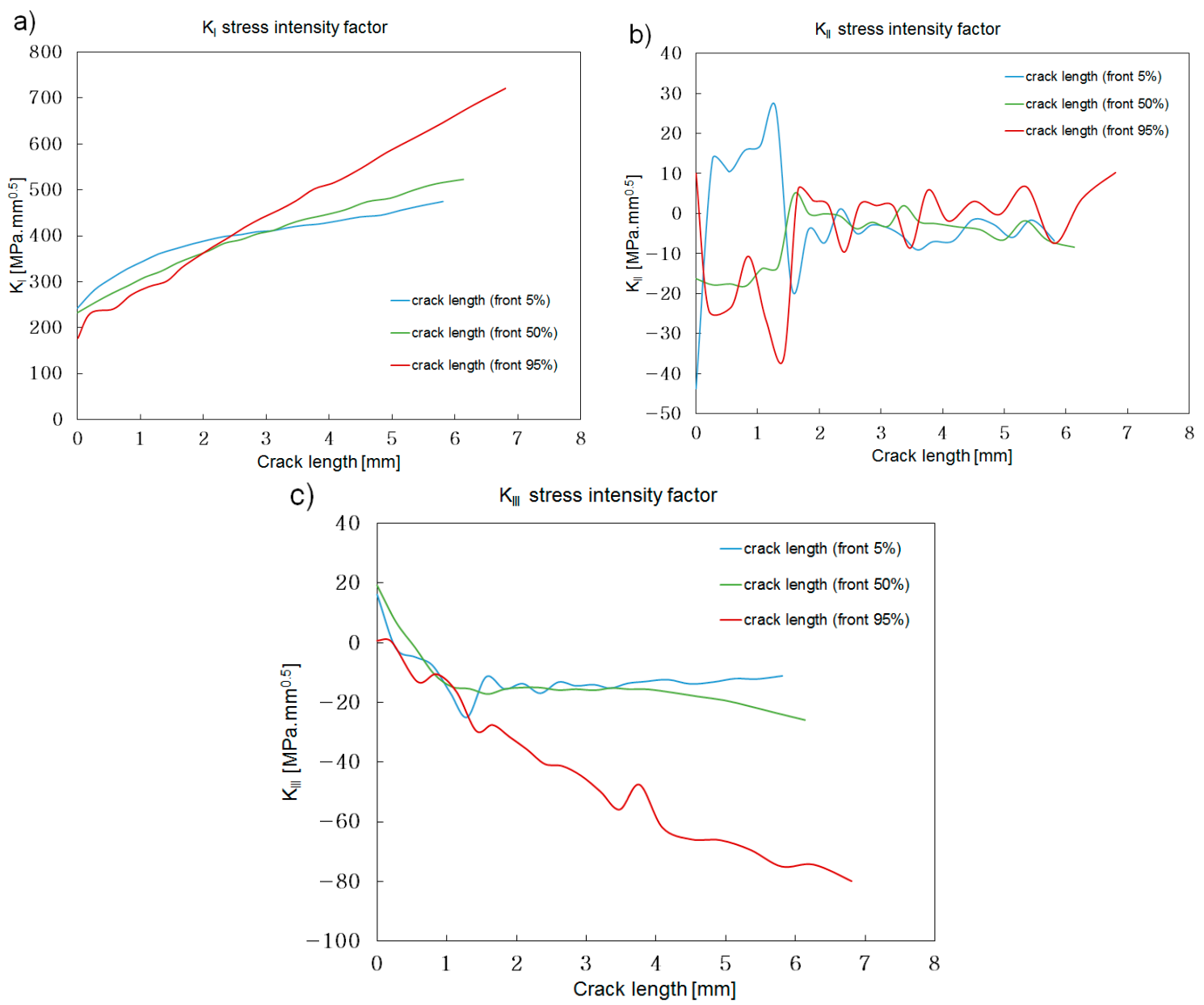

Figure 21. The $45^{\circ}$ angle, long flank. Stress intensity along the three crack paths selected: (a) $\mathrm{K}_{\mathrm{I}}$; (b) $\mathrm{K}_{\mathrm{II}}$; (c) $\mathrm{K}_{\mathrm{III}}$.

It can be noticed that most critical crack path is at $95 \%$ of the crack front. After a certain crack length, effects of $\mathrm{K}_{\mathrm{III}}$ start playing a major role on crack propagation.

\subsection{Effects of the Flank Angle: A Comparison}

In this section, a comparison of the results of different flank angles is given. The comparison is always performed at the $95 \%$ of the crack front. This is to avoid the solution singularity at the free surface of the crack that results from the Franc3D algorithm. The results of the short flank length are shown in Figure 22. 


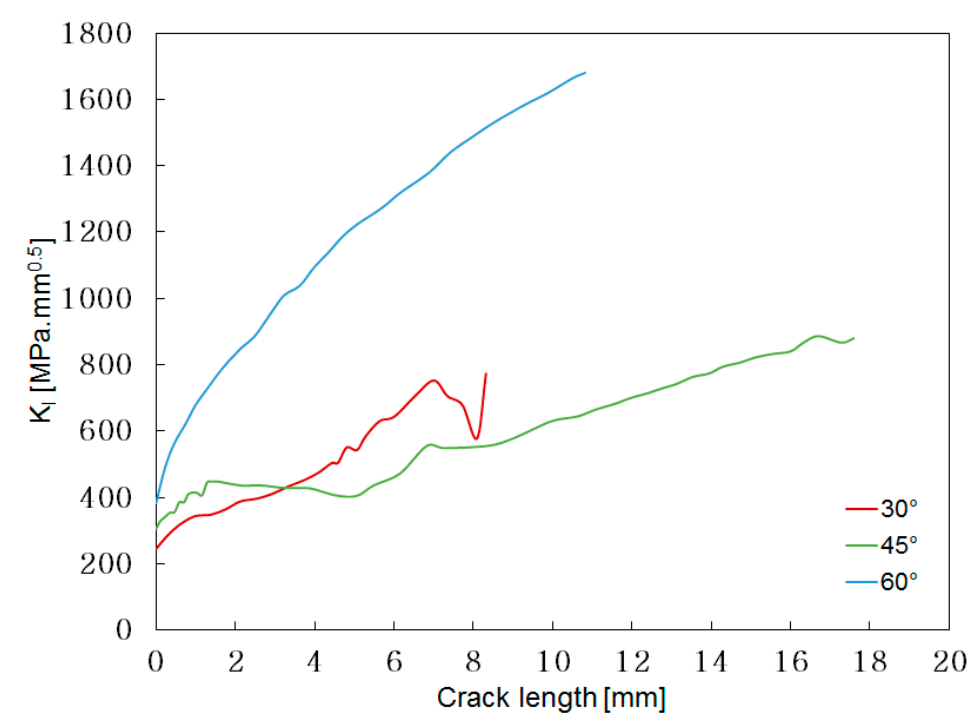

Figure 22. Comparison of the different flank angles at 95\% crack front for the short flank design option: KI stress intensity factor.

At small crack sizes, the $\mathrm{K}_{\mathrm{I}}$ solution of the $45^{\circ}$ angle flank blade had an intermediate trend between the other two angle flank designs. However, the crack changed its growth direction and $\mathrm{K}_{\mathrm{I}}$ trend became lower than the other flank angle designs, at a crack size bigger than $3 \mathrm{~mm}$. This is thought to be related to the selected blade geometric parameters. i.e., this behavior could be specific to blade design. This, however, requires more simulations or testing to validate this assumption.

The analogous results for the long flank design options are given in Figure 23. The trend is analogous to the one observed for the short flank option with the only difference $45^{\circ}$ angle starts to be beneficial for a longer crack length (c.a. $6 \mathrm{~mm}$ ).

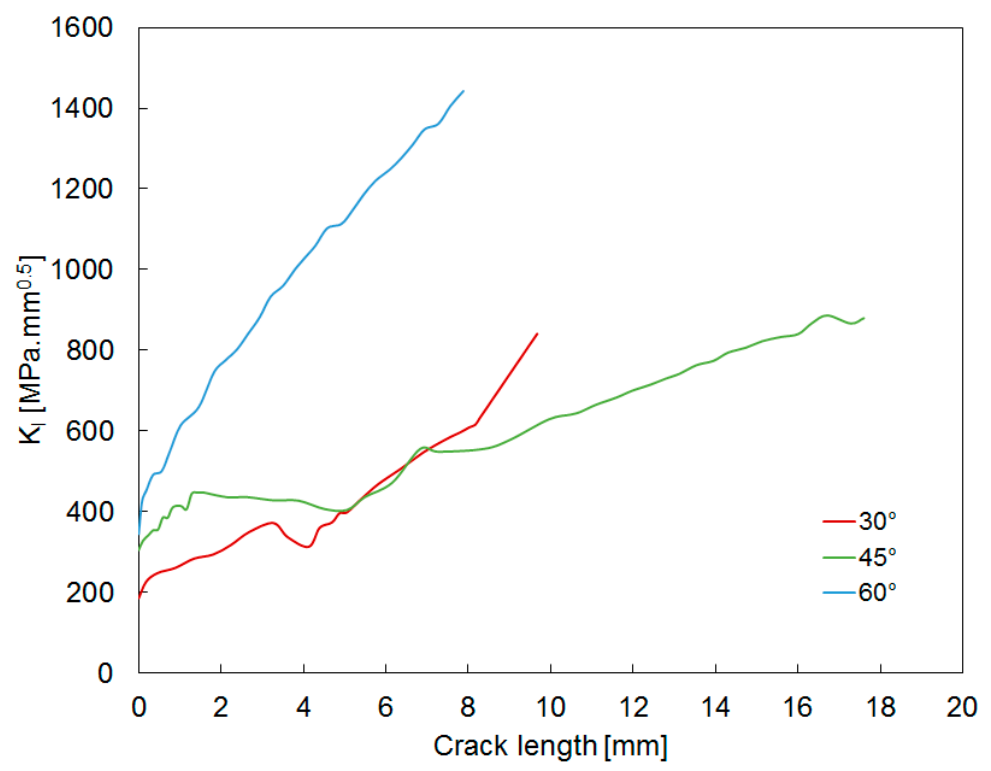

Figure 23. Comparison of the different flank angles at 95\% crack front for the long flank design option: $\mathrm{K}_{\mathrm{I}}$ stress intensity factor. 
The main conclusion of this comparison is that: the $45^{\circ}$ angle is beneficial because it helps reduce the stress intensity factor KI when the crack approaches critical values closer to the fracture toughness.

\subsection{Effects of the Flank Contact Length: A Comparison}

A comparison of all the design angles was made in terms of long against short flank options. It must be remarked that the short flank is preferable in terms of weight penalty. In order to consider the possibility of choosing a longer flank design, there must be a justified technical reasoning in terms of crack initiation (due to the stress distribution) and crack propagation, which is the objective of the present study. A comparison of $K_{I}$ at $95 \%$ crack front for all geometries is given in Figure 24 . For the $30^{\circ}$ and $60^{\circ}$ flank angles, the stress intensity variation from having a shorter flank is very small. For the $45^{\circ}$ flank angle, the short flank design option is even beneficial.

This is due to the fact that the contact pressure is not uniformly distributed on the contact surface. A peak of stress in the area of the edge of contact exists in any case, independently of the flank length.
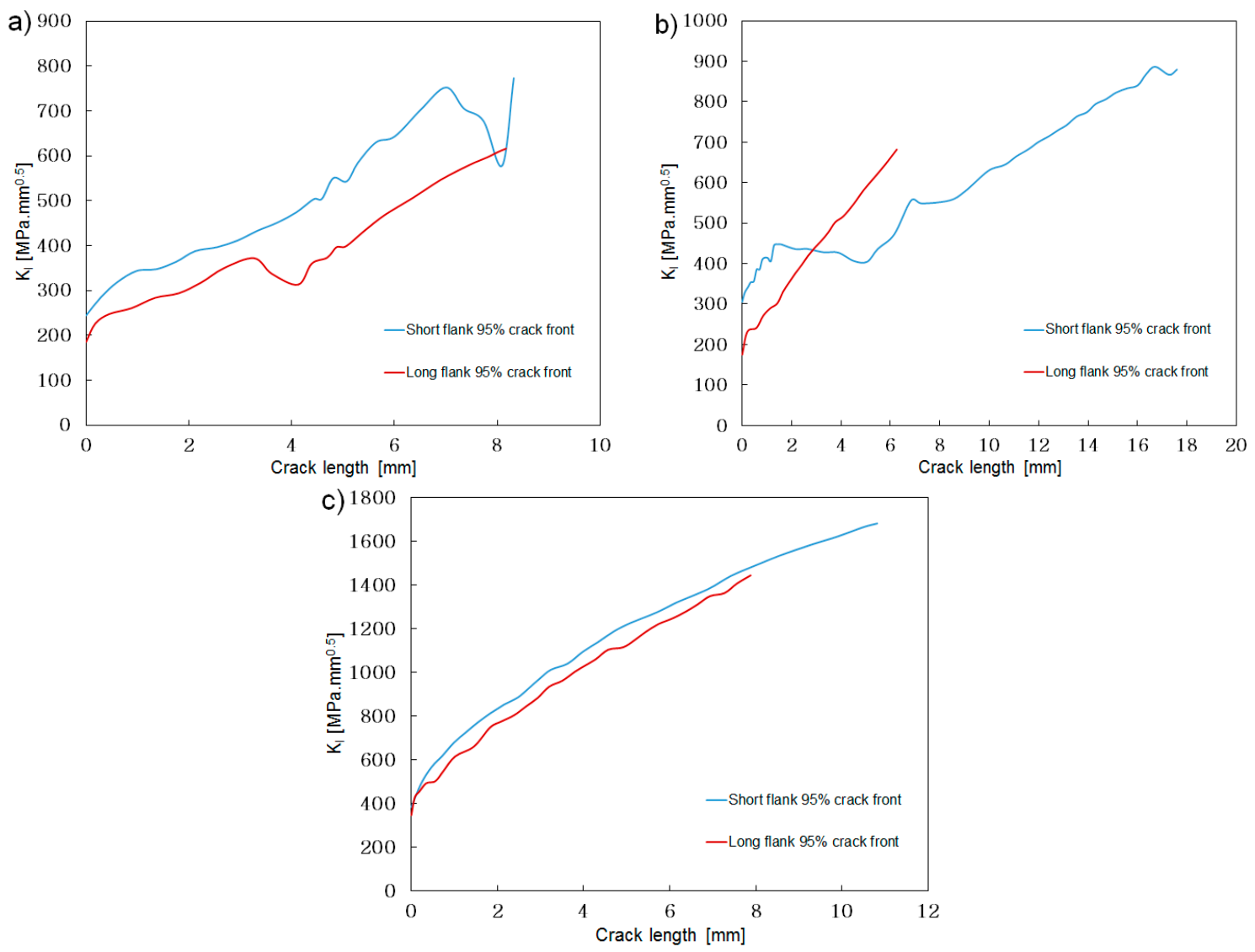

Figure 24. Short vs. long flank for all the flank angle design options: (a) $30^{\circ}$; (b) $45^{\circ}$; (c) $60^{\circ}$.

\subsection{Effects of the Friction Coefficient: A Comparison}

In order to study the effect of friction, the $45^{\circ}$ short flank model was analysed using two different friction coefficients. A friction coefficient $\mu=0.7$ is useful to simulate a worn flank, whilst a friction coefficient $\mu=0.1$ is useful to understand the behavior of a perfectly lubricated dovetail contact. At $95 \%$ crack front, a back-to-back comparison is shown in Figure 25. 


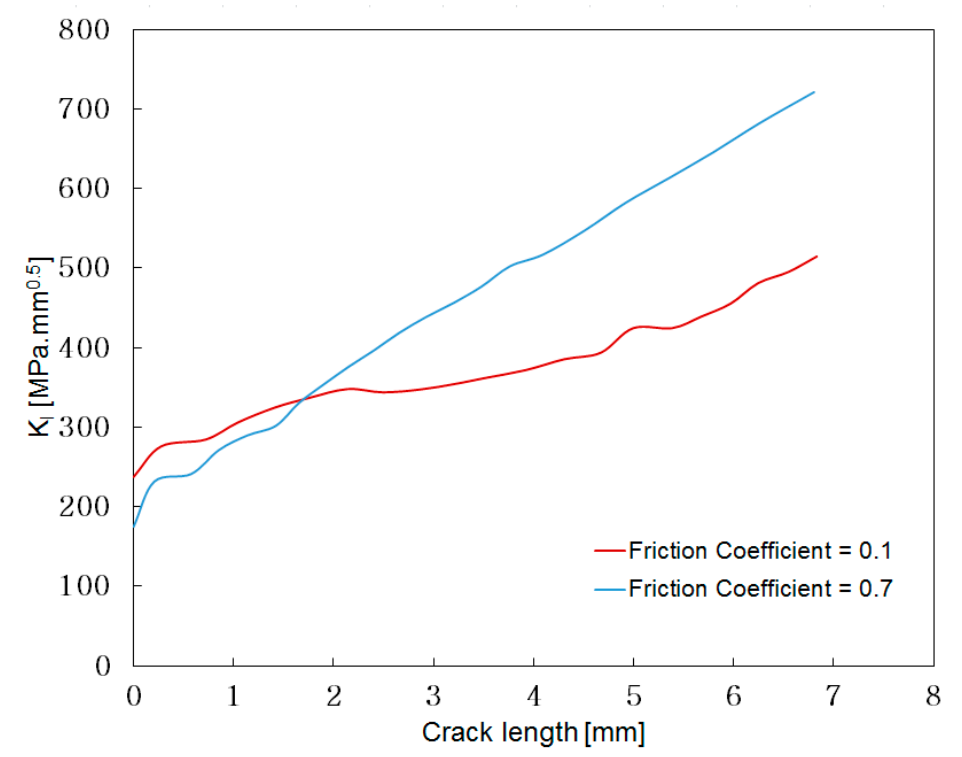

Figure 25. Crack propagation behavior with low and high metal-to-metal friction coefficient. The geometry is a $45^{\circ}$ short flank, $95 \%$ crack front.

As expected, a lower friction coefficient implies the blade can slide further up the blade flank and hence a reduction of the stress fields and the crack propagation is slower, especially when the crack is growing longer than $>2 \mathrm{~mm}$.

An overview of the crack shape difference between the low and high friction is shown in Figure 26.

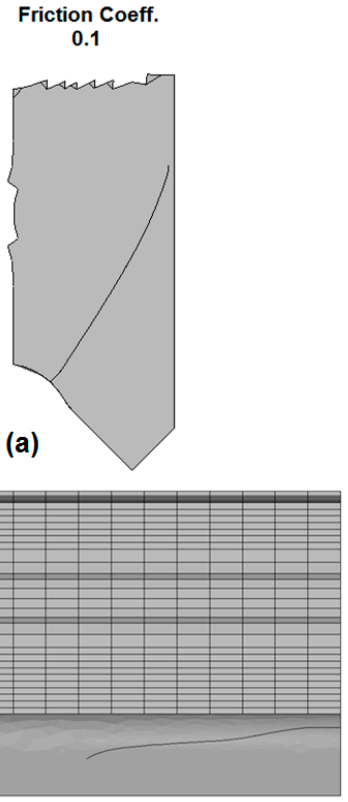

(b)
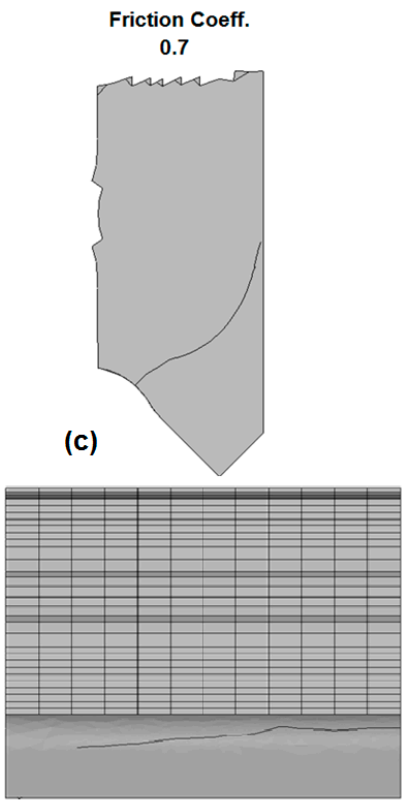

(d)

Figure 26. Crack shape and direction. A direct comparison between low and high friction coefficients. The geometry is a $45^{\circ}$ short flank. (a) Friction coefficient $=0.1$ front view; (b) Friction coefficient $=0.1$ top view; (c) Friction coefficient $=0.7$ front view $(\mathbf{d})$ Friction coefficient $=0.1$ top view. 


\subsection{Effects of $K_{\text {eq }}$}

A crack subjected to three-dimensional mixed-mode loading is capable of growth if $\Delta \mathrm{K}_{\mathrm{eq}}>\Delta \mathrm{K}_{\mathrm{th}}$. In other words, the crack propagates if a stress intensity factor written as a function of $\mathrm{K}_{\mathrm{I}}, \mathrm{K}_{\mathrm{II}}$, and $\mathrm{K}_{\mathrm{III}}$ (and not $\mathrm{K}_{\mathrm{I}}$ alone) exceeds the propagation threshold. The Franc3D analysis was repeated by using $\mathrm{K}_{\mathrm{eq}}$ instead of $\mathrm{K}_{\mathrm{I}}$ for the $45^{\circ}$ short flank geometry. This numerical simulation is relevant as it was observed that $\mathrm{K}_{\mathrm{II}}$ and even most importantly $\mathrm{K}_{\mathrm{III}}$ may play a relevant role in such complex cracking scenarios.

The value of $K_{e q}$ used was taken from reference [14] and it is given in Equation (2).

$$
\Delta K_{e q}=\frac{\Delta K_{I}}{2}+\frac{\sqrt{\Delta K_{I}^{2}+5.336 \Delta K_{I I}^{2}+4 \Delta K_{I I}^{2}}}{2}
$$

This 3D mixed-mode criterion was compared with other criteria available in the open literature (like Pook and Schoellmann) [23] and very small difference was found in terms of crack propagation (direction, kink, twist angle, and so on).

A comparison between a propagation driven by $\mathrm{K}_{\mathrm{I}}$ alone and a propagation driven by $\mathrm{K}_{\mathrm{eq}}$ is shown in Figure 27. The geometry analysed is the $45^{\circ}$ short flank.

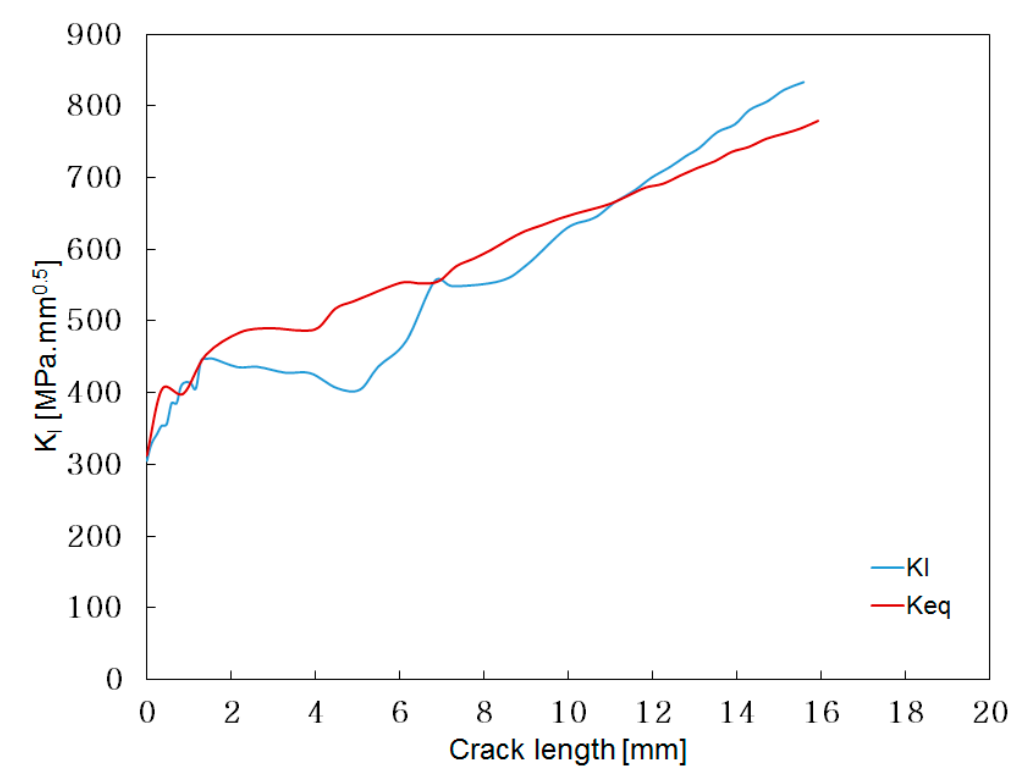

Figure 27. Comparison between a $K_{\mathrm{I}}$ and a $K_{\mathrm{eq}}$ driven crack for a $45^{\circ}$ short flange geometry, $95 \%$ crack front.

It could be clearly observed that the $\mathrm{K}_{\mathrm{eq}}$ is higher than considering only the $\mathrm{K}_{\mathrm{IC}}$ failure criterion when the crack is relatively short. After a certain length, however, the crack behaviour remains almost unaffected until $12 \mathrm{~mm}$ crack length. Compared to that size, the $\mathrm{K}_{\mathrm{I}}$ will have a higher trend than $\mathrm{K}_{\mathrm{eq}}$. The different crack shapes are shown in Figure 28. It can be seen that the long path of the crack will deviate in such a way as to be able to follow the edge of the contact. 

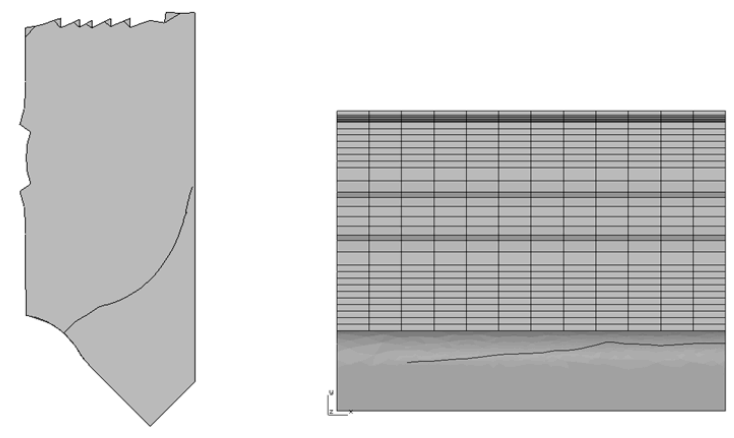

$\kappa_{\text {eq }}$
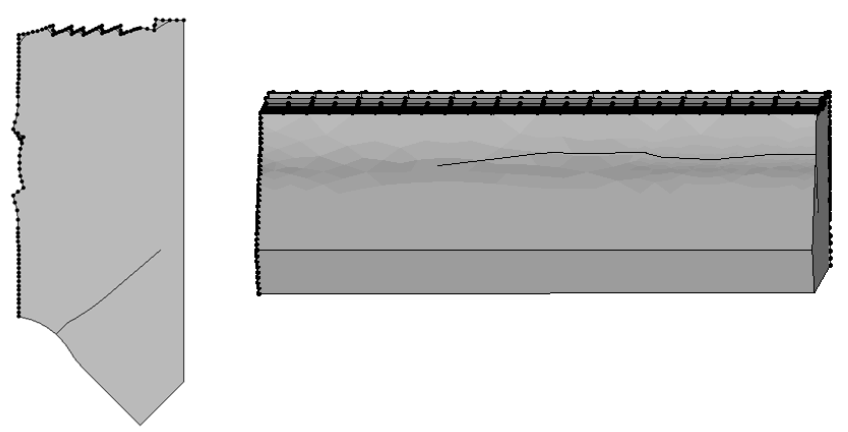

Figure 28. Crack shape and direction, a direct comparison between $\mathrm{K}_{\mathrm{I}}$ and $\mathrm{K}_{\text {eq. }}$. The geometry is a $45^{\circ}$ short flank.

\subsection{Untwist and Tip Clearances}

Understanding the crack progression on a blade root is not only important from the structural integrity point of view, but also in terms of displacements. The crack progression, in fact, may affect the displacements of the tip of the blade, both at the leading and trailing edge. Consequently, the untwist may be affected and even the entire performance of the subsystem it works within or its stability (surge may be caused by an excess of tip clearance). With the term "untwist" the reduction in the angle of torsion induced by the centrifugal force of a rotating component in a turbomachinery is meant. The initial angle of twist $\varphi$ (undeformed geometry) is $30^{\circ}$ for all the geometries analysed (Figure 29). Such an angle tends to become smaller when the centrifugal load is applied. The variation from this original angle is the "untwist".

It is also useful to monitor the vertical displacements of point A (the leading edge tip) and point B (the trailing edge tip). Such a parameter is of particular interest when assessing tip clearances in a sub-system, such as axial compressors or turbines. 


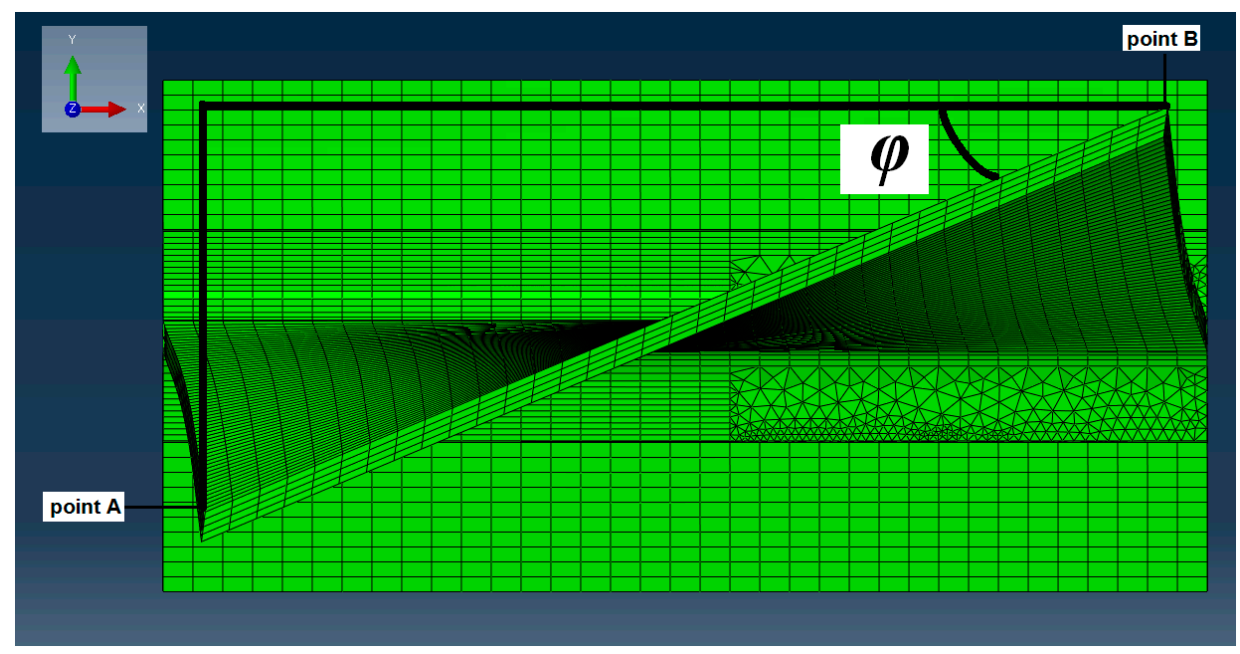

Figure 29. Definition of angle of twist. Its reduction when a centrifugal load is applied is called "untwist".

The results of such a deformation as a function of the crack progression are given in Tables 6 and 7 for the short flanks geometries with $30^{\circ}$ and $60^{\circ}$ flank angles.

Table 6. Deformation results for the $30^{\circ}$ short flank geometry.

\begin{tabular}{cccc}
\hline $\begin{array}{c}\text { Crack Length } \\
{[\mathrm{mm}]}\end{array}$ & $\begin{array}{c}\text { Untwist } \\
\text { [Degrees] }\end{array}$ & $\begin{array}{c}\text { LE Vertical Deflection } \\
{[\mathrm{mm}]}\end{array}$ & $\begin{array}{c}\text { TE Vertical Deflection } \\
{[\mathrm{mm}]}\end{array}$ \\
\hline 0 & -7.2218 & 0.8828 & 0.7257 \\
1.3738 & -7.2202 & 0.8826 & 0.726 \\
2.0152 & -7.2157 & 0.8821 & 0.7268 \\
3.3353 & -7.2139 & 0.8819 & 0.7276 \\
6.5189 & -7.2054 & 0.8806 & 0.7297 \\
\hline
\end{tabular}

Table 7. Deformation results for the $60^{\circ}$ short flank geometry.

\begin{tabular}{cccc}
\hline $\begin{array}{c}\text { Crack Length } \\
{[\mathbf{m m}]}\end{array}$ & $\begin{array}{c}\text { Untwist } \\
\text { [Degrees] }\end{array}$ & $\begin{array}{c}\text { LE Vertical Deflection } \\
{[\mathbf{m m}]}\end{array}$ & $\begin{array}{c}\text { TE Vertical Deflection } \\
{[\mathbf{m m}]}\end{array}$ \\
\hline 0 & -7.1913 & 0.9823 & 0.8126 \\
1.262 & -7.1874 & 0.9818 & 0.8137 \\
2.722 & -7.1787 & 0.9807 & 0.8163 \\
4.343 & -7.1639 & 0.9788 & 0.8207 \\
6.886 & -7.132 & 0.9752 & 0.8299 \\
9.894 & -7.0661 & 0.969 & 0.8468 \\
10.816 & -7.0595 & 0.9671 & 0.8524 \\
\hline
\end{tabular}

It can be noted that the deformation was not heavily affected. This happened because the blade root was heavily constrained within the disc slot as shown in Figures 6 and 7. As the crack progressed, a different distribution of stress was observed. The area of contact immediately close to the crack front tends to experience a stress relief whilst the undamaged area of the flank tends to experience a stress increase as shown in Figure 30. 


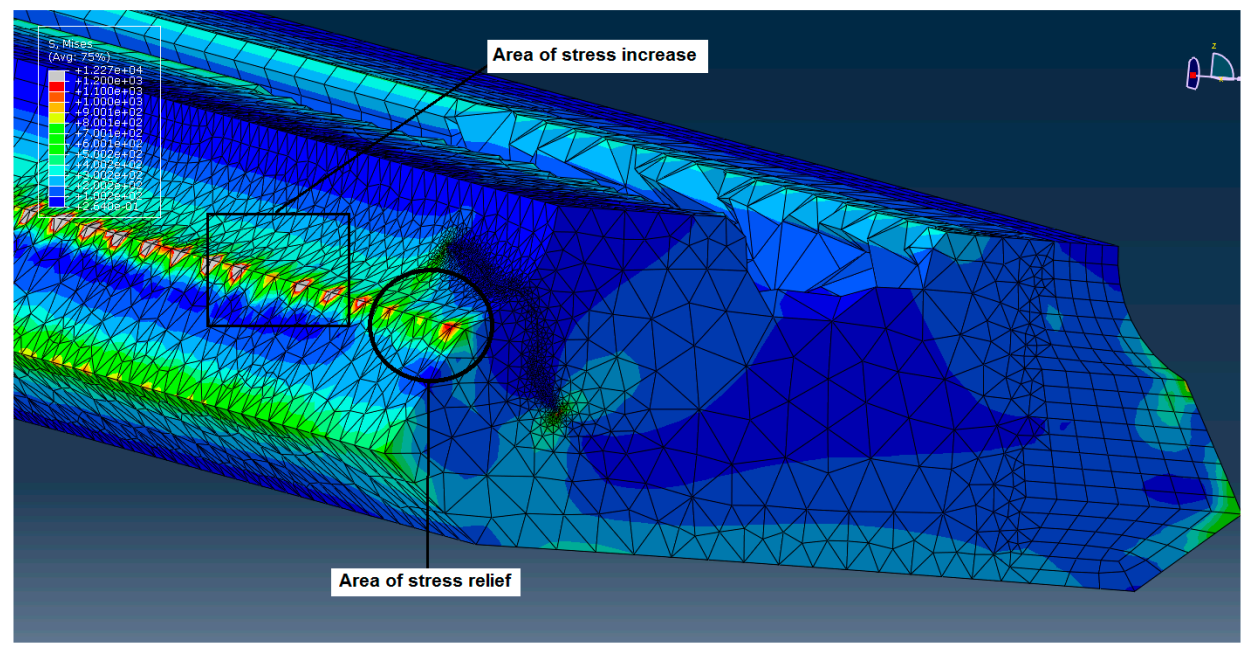

Figure 30. Contact flank stress re-distribution as a function of the crack progression.

It is important to remark that because of the above-mentioned re-distribution, cracks other than the one analysed may be initiated and propagate. This phenomenon has not been taken into account in this work.

\subsection{Damage Tolerant Cycles: An Example}

A design value of $800 \mathrm{MPa} \mathrm{mm}^{0.5}$ was taken as the critical fracture toughness. Equation (1) was used to calculate the damage tolerant life of each design solution. Results are given in Table 8.

Table 8. Damage tolerant life of the analysed geometries.

\begin{tabular}{|c|c|c|c|c|}
\hline Geometry & $\begin{array}{c}\text { Flank } \\
\text { Length }\end{array}$ & $\begin{array}{l}\text { Friction } \\
\text { Coefficient }\end{array}$ & $\begin{array}{l}\text { Crack Length at } \\
810 \mathrm{MPa} \mathrm{mm}^{0.5}\end{array}$ & $\begin{array}{l}\text { Number of Cycles } \\
\text { at } 810 \mathrm{MPa} \mathrm{mm}^{0.5}\end{array}$ \\
\hline $45^{\circ}$ & Short & 0.7 & 14.73 & 17,842 \\
\hline $45^{\circ}$ & Long & 0.7 & 7.80 & 17,644 \\
\hline $45^{\circ}$ & Short & 0.1 & 11.16 & 17,805 \\
\hline $60^{\circ}$ & Short & 0.7 & 1.845 & 16,528 \\
\hline $60^{\circ}$ & Long & 0.7 & 2.38 & 16,836 \\
\hline $30^{\circ}$ & Short & 0.7 & 8.61 & 17,681 \\
\hline $30^{\circ}$ & Long & 0.7 & 9.98 & 17,734 \\
\hline
\end{tabular}

The difference between the residual life of the different geometries is not a significant number. It can however be noticed that the $45^{\circ}$ flank with short flank offers the best damage tolerance option. This is also true in terms of crack length reached at the design fracture toughness. The " $45^{\circ}$ degrees short" can tolerate longer cracks without catastrophic failure.

\section{Conclusions}

Several blade dovetail root geometries with different flank angles and lengths were analysed with the same structural loads under the same initial flaw, by using Franc3 $\mathrm{D}^{\odot}$ and Abaqus. Effects of friction coefficient and the utilisation of an equivalent $K_{\text {eq }}$ calculation method were also studied. The following was concluded:

- The $45^{\circ}$ flank angle offers a lower crack propagation rate compared to the $30^{\circ}$ and $60^{\circ}$ geometries. In other words, the damage tolerant life offered by the $45^{\circ}$ solution is better than the other two flank angle options.

- For a given crack length, the stress intensity $\mathrm{K}_{\mathrm{I}}$ given by the short and long flank (for given flank angle) is comparable. The short flank has, in some cases, slightly higher values of stress intensity 
factors, but a design choice of longer flank will have the disadvantage of increasing the weight of the structure only to obtain a negligible advantage in terms of crack propagation. This advantage would not exist in the $45^{\circ}$ design option.

- The untwist of the leading and trailing edge tip displacements are virtually unaffected by the crack propagation. The stress re-distribution along the flank length, however, may induce the nucleation and propagation of different (and numerous) crack fronts. This case has not been considered in this work.

- The reaction, $R$, and hence the friction force on the flank surface, $\mu R$, increase inversely with $\vartheta$, i.e., $R \propto 1 /(\cos \vartheta)$. Once the blade is loaded under centrifugal force, the friction at the flank surface will restrain the blade from sliding up against the disc flank and hence more strain energy would be released at the crack front which will extend the crack further towards the blade root. In other terms, the higher the friction, the faster the crack would propagate.

- A low friction coefficient (given for example by a lubricated contact) is beneficial in slowing down the crack propagation, even if its influence is not as massive as expected.

- Setting the failure criterion in Franc3D to $K_{I}$ will have no significant difference from using $K_{\text {eq }}$ to calculate the $\mathrm{K}$ at crack sizes below $12 \mathrm{~mm}$ as the contribution of other modes in the $\mathrm{K}_{\text {eq }}$ equation is not significant. However, more simulations would be required to confirm this trend for higher crack sizes and blade geometries.

- No influence of vibration was studied. This will be part of future investigations.

Author Contributions: Formal analysis, G.C. and M.K.; Visualization, A.M. and P.S.; Writing—original draft, G.C. and M.K.; Writing-review \& editing, A.M., P.S. and R.C.

Funding: This research received no external funding.

Acknowledgments: The authors would like to thank John Schofield, John Bolger, Richard Coghlan (Rolls-Royce plc, Derby, UK), and Felice Rubino for their ongoing support. Without their contribution this work would not have been possible.

Conflicts of Interest: The authors declare no conflict of interest exists as a result of publishing this work.

\section{References}

1. Barlow, K.W.; Chandra, R. Fatigue crack propagation in an aircraft engine fan blade attachment. Int. J. Fatigue 2005, 27, 1661-1668. [CrossRef]

2. Poursaeidi, E.; Bakthtini, H. Fatigue crack simulation in a first stage of compressor blade. Eng. Fail. Anal. 2014, 45, 314-325. [CrossRef]

3. Poursaeidi, E.; Salavatien, M. Fatigue crack growth simulation in a generator fan blade. Eng. Fail. Anal. 2009, 16, 888-898. [CrossRef]

4. Giannella, V.; Vivo, E.; Mazzeo, M.; Citarella, R. FEM-DBEM approach to simulate crack propagation in a turbine vane segment undergoing a fatigue load spectrum. Procedia Struct. Integr. 2018, 12, $479-491$. [CrossRef]

5. Giannella, V.; Perrella, M.; Shlyannikov, V.N. Fatigue crack growth in a compressor stage of a turbofan engine by FEM-DBEM approach. Procedia Struct. Integr. 2018, 12, 404-415. [CrossRef]

6. Citarella, R.; Giannella, V.; Vivo, E.; Mazzeo, M. FEM-DBEM approach for crack propagation in a low pressure aeroengine turbine vane segment. Theor. Appl. Fract. Mech. 2016, 86, 143-152. [CrossRef]

7. Giannella, V.; Dhondt, G.; Kontermann, C.; Citarella, R. Combined static-cyclic multi-axial crack propagation in cruciform specimens. Int. J. Fatigue 2019, 123, 296-307. [CrossRef]

8. Cornell Fracture Group, Cornell University. Available online: www.cfg.cornell.edu (accessed on 11 November 2018).

9. Cornell Fracture Group. FRANC3D Menu E Dialog Reference; Cornell University: Ithaca, NY, USA, 2002.

10. Seifi, R.; Omidvar, N. Fatigue crack growth under mixed mode I+III loading. Mar. Struct. 2013, 34, 1-15. [CrossRef] 
11. Aygül, M.; Al-Emrani, M.; Barsoum, Z.; Leander, J. An investigation of distortion-induced fatigue cracking under variable amplitude loading using 3D crack propagation analysis. Eng. Fail. Anal. 2014, 45, 151-163. [CrossRef]

12. Pettit, R.; Annigeri, B.; Owen, W.; Wawrzynek, P. Next generation 3D Mixed Mode fracture propagation theory including HCF-LCF interaction. Eng. Fract. Mech. 2013, 102, 1-14. [CrossRef]

13. Giannella, V.; Citarella, R.; Perrella, M.; Shlyannikov, V. Surface crack modelling in an engine compressor disc. Theor. Appl. Fract. Mech. 2019, 103, 102279. [CrossRef]

14. Richard, H.A.; Sander, M. Fatigue Crack Growth Detect-Assess-Avoid; Springer: Berlin/Heidelberg, Germany, 2016.

15. Saigal, A.; Zhan, K.; Chan, T.S. Forging of compressor blades: Temperature and ram velocity effects. J. Eng. Gas Turbines Power 1995, 117, 528-533. [CrossRef]

16. Meetham, G.W. The Development of Gas Turbine Materials; Applied Science Publisher; Springer: Berlin/Heidelberg, Germany, 1981.

17. Ma, H.; Wang, D.; Tai, X.; Wen, B. Vibration response analysis of blade-disc dovetail structure under blade tip rubbing condition. J. Vib. Control 2015, 23, 252-271. [CrossRef]

18. Zhu, Y.; Xiong, J.; Lv, Z.; Zhao, Y. Testing and Evaluation for fatigue crack propagation of Ti-6Al-4Va/ELI and 7050-T7452 alloys at high temperatures. Chin. J. Aeronaut. 2018, 31, 1388-1398. [CrossRef]

19. Ritchie, R.O.; Davidson, D.L.; Boyce, B.L.; Campbell, J.P.; Roder, O. High Cycle Fatigue of Ti-6Al-4Va. Fatigue Fract. Eng. Mater. Struct. 1999, 22, 621-631. [CrossRef]

20. Carter, B.; Wawrzynek, P. Franc3D Reference Manual; Version 7; Fracture Analysis Consultants, Inc.: New York, NY, USA, 2016.

21. Ashoaibi, A.M.; Ariffin, A.K. Evaluation of Stress Intensity Factor Using Displacement Correlation Techniques. J. Kejuruteraan 2008, 20, 75. [CrossRef]

22. Dias, D.E. SIF Calculations for Multistable Damage Using Franc3d. Master's Thesis, University of Bandung, Bandung, Indonesia, 2008.

23. Richard, H.A.; Eberlein, A. Material characteristics at 3D mixed mode loading. In Proceedings of the 21st European Conference on Fracture, ECF21, Catania, Italy, 20-24 June 2016.

(C) 2019 by the authors. Licensee MDPI, Basel, Switzerland. This article is an open access article distributed under the terms and conditions of the Creative Commons Attribution (CC BY) license (http://creativecommons.org/licenses/by/4.0/). 